\title{
STRUCTURE OF A HEAVILY TRANSCRIBED REGION OF BARLEY CHLOROPLAST DNA.TRANSFER RNA GENES FOR SERINE (UGA), GLYCINE (GCC,UCC), FORMYL-METHIONINE AND THREONINE (GGU)
}

\author{
by
}

RICHARD P. OLIVER") and CARSTEN POULSEN ${ }^{2 \prime}$

Department of Physiology, Carlsberg Laboratory, Gamle Carlsbergvej 10, DK-2500, Copenhagen Valby

Present addresses: ") School of Biological Sciences, University of East Anglia,Norwich NR4 7TJ, England

${ }^{2)}$ Laboratory of Plant Molecular Biology, The Rockefeller University, New York, NY, USA

Keywords: Repeated sequences. Introns. Multiple transcripts. Intercistronic processing

The barley chloroplast genome is transcribed into at least 80 RNA molecules (29). Some regions of the genome hybridise to more transcripts than others. One $4.3 \mathrm{kbp}$ HindllI fragment was found to hybridise to a dispropartionately high number of transcripts, some of which were light-induced. The sizes of the transcripts ranged from 0.3 to $5.5 \mathrm{~kb}$. In order to discover from which genes these transcripts are derived, the DNA sequence of the fragment has been determined and the transcripts have been mapped. Five tRNA genes have been located including genes for formyl-methionine tRNA and a glycine tRNA with an intron in the D-stem. A scheme to account for the transcription and processing of a precursor-transcript for these tRNAs is proposed. A region containing two open-reading frames hybridises to 9 transcripts. The largest of these, which is $5.5 \mathrm{~kb}$, may be intercistronically processed. A number of long repeated sequences which may be involved in recombinational activity were found.

\section{INTRODUCTION}

Chloroplasts contain multiple copies of a circular DNA molecule of about 115 to $180 \mathrm{kbp}$ (45). The genome of barley is typical of many higher plants. It is about $135 \mathrm{kbp}$ and contains inverted repeats of $21 \mathrm{kbp}$ (29). In an earlier study, more than $80 \%$ of the genome was cloned in bacterial vectors (29). Selected DNA fragments which had been isolated and nick-translated, were hybridised to electrophoretically separated filter-bound chloroplast RNA. This study revealed more than 70 discrete RNA transcripts of the genome. The transcripts were not distributed evenly around the genome. One $4.3 \mathrm{kbp}$ Hindlil fragment, cloned in the plasmid $\mathrm{pHvC} 35$, was found to hybridise to at least 10 transcripts ranging from $300 \mathrm{~b}$ to more than $5 \mathrm{~kb}$. Moreover, at least 4 of these were found to be more abundant in plastid RNA isolated from plants illuminated for 8 hours, than in etioplast RNA. This indicated that these transcripts were light-induced.

The disproportionately heavy transcription of this region prompted the present study. The DNA sequence has been determined and the transcripts mapped. Five tRNA genes have been

Abbreviations: $b=$ base; $k b=$ kilo base; $k b p=$ kilo base pairs; $O R F=$ open reading frame; $p H v C=$ recombinant plasmid containing a barley chloroplast DNA fragment; $\operatorname{trn} X-Y Z Z=t R N A$ gene for amino acid $X$, anticodon $Y Z Z$ 


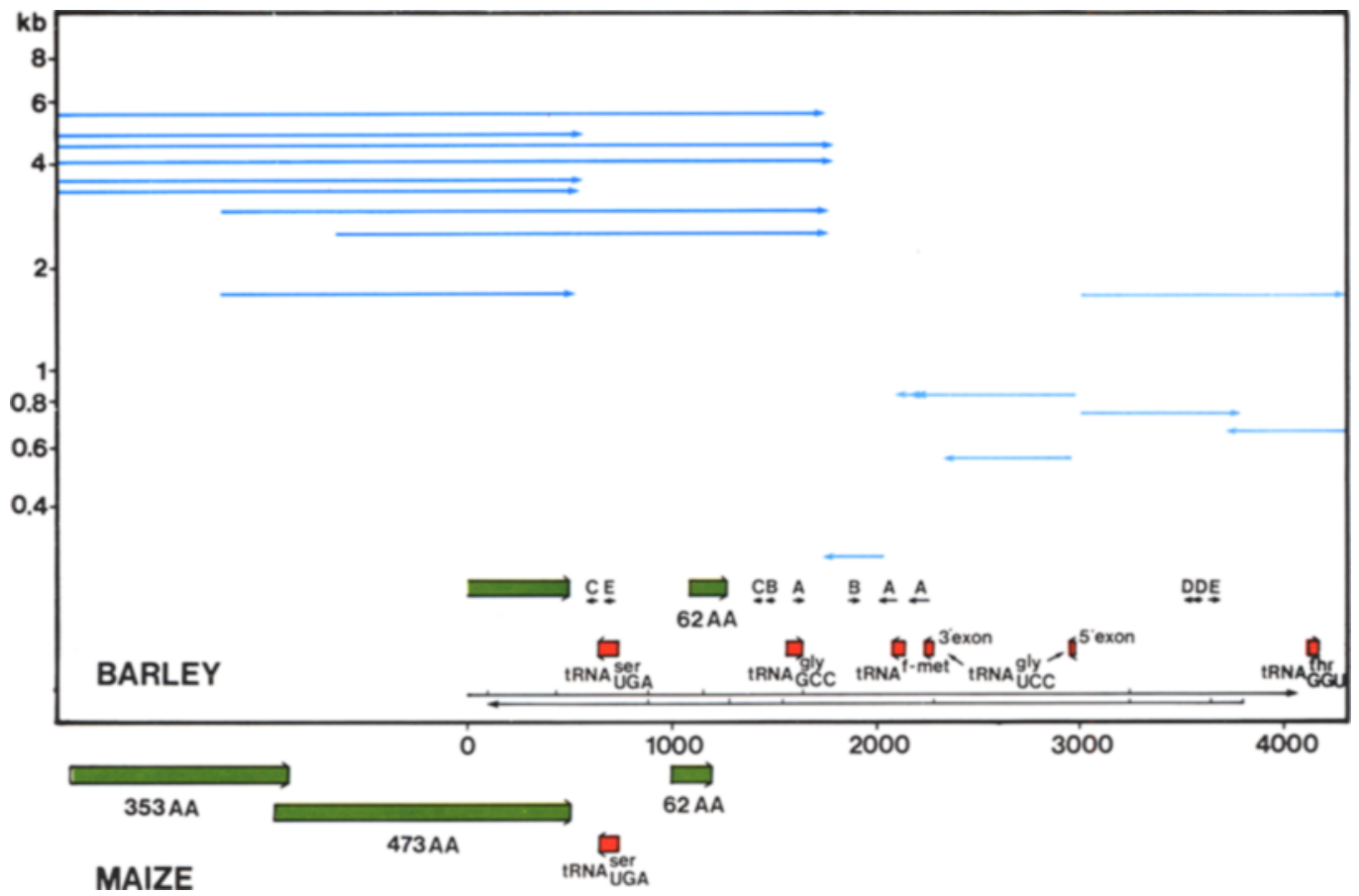

Figure 1. Summary of the DNA sequence analyses and transcript mapping of $\mathrm{pHvC} 35$. The horizontal scale represents the 4294 bases of the sequence. Green arrows = open-reading frame; red arrows = LRNA genes; black arrow $=$ repeated sequence. The vertical scale indicates the size of constitutive transcripts (dark-blue) and light-induced transcripts (light-blue). The M13-probes used for transcript mapping are shown just above the abscissa.

identified. These include genes for the initiating methionine $T R N A$ and for a glycine tRNA with an intron in the D-stem. Sequences corresponding to the 3 ' portion of a long open-reading frame (ORF) hybridise to 9 transcripts. This multiplicity of colinear transcripts indicates extensive processing of the primary transcript. A number of tandem and inverted repeats of $16-40 \mathrm{~b}$ were found. This may indicate that this region of the plastid genome is active in recombination $(3,11$, 42).

Preliminary data and summaries of this work have appeared elsewhere $(31,32,44)$.

\section{MATERIALS AND METHODS}

\subsection{Nucleic acids}

DNA of the plasmid pHvC35, which contains a $4.3 \mathrm{kbp}$ HindIII fragment inserted in the tetracycline resistance gene of pBR322, was prepared according to BIRNBOIM and DOLY (2).
M13mp8 and M13mp9 (24) replicative forms were gifts from S.K. RASMUSSEN.

Plastid RNA was prepared from etioplasts and chloroplasts by lysis in guanidinium thiocyanate and centrifugation through a cushion of $\mathrm{CsCl}$ (29). In some experiments plastids were extracted with phenol and chloroform and and the nucleic acid precipitated directly. These preparations contained DNA and small mol. wt. RNA as well as large mol. wt. RNA.

\subsection{DNA sequencing}

Restriction endonuclease digests (HindIII, Sall, BamHI, EcoRI, PstI, Xbal, EcoRI ${ }^{\mathrm{x}}$, RsaI, Hpal, TaqI and Sau3A) of pHvC35 or its subclones were ligated randomly into the appropriately cleaved replicative form of $\mathrm{M} 13 \mathrm{mp} 8$ or M13mp9 (24). After transfection into E. coli JM101 recombinants were propagated and sequenced as described $(34,35)$. Extra data were 


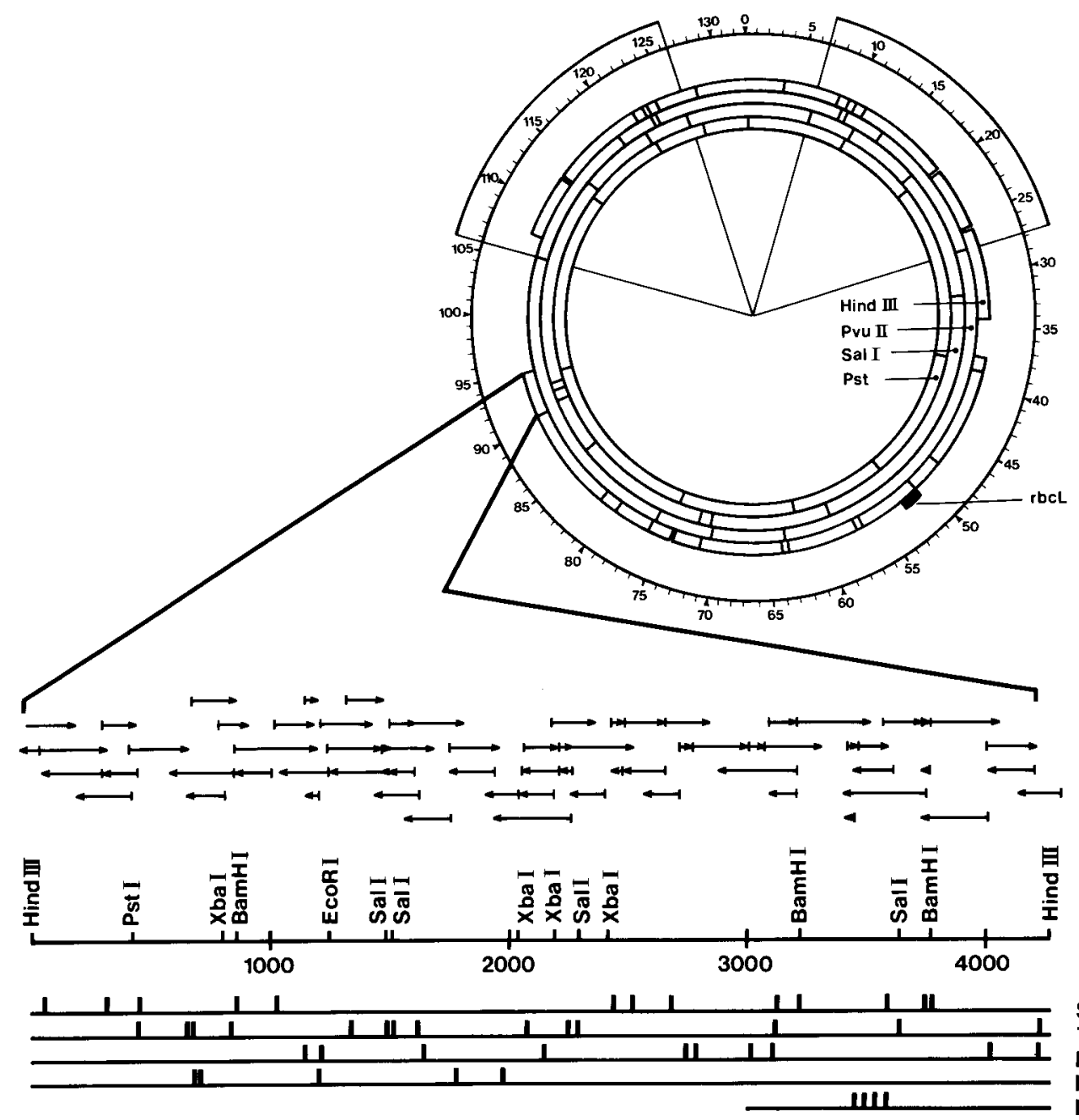

Sau 3A Taq I Rsa I Hpa II EcoR I*

Figure 2. Physical map of barley chloroplast DNA showing the location and orientation of pHvC35 DNA. The cleavage sites of the restriction enzymes used in the sequence analysis are indicated. Only one small BamHI fragment was digested with EcoR ${ }^{*}$. Black arrows represent the direction and extent of sequence information obtained from each M13 subclone.

obtained from one clone which contained a SalI fragment corresponding to nucleotides 2294 to 1598 in the sequence (Figure 2). A $168 \mathrm{bp} \mathrm{XbaI}$ fragment (nucleotides 2204 to 2036) was removed by digesting replicative form DNA with $\mathrm{XbaI}$ and electrophoresis on a low-melting point agarose gel. The large fragment was purified, ligated, transfected and sequenced. Sequence data were analysed using a Honeywell Bull computer and the programs of Dr. R. STADEN (MRC, LMB, Cambridge, UK).

\subsection{Transcript mapping}

Chloroplast RNA was electrophoresed in $1.5 \%$ Seakem agarose gels containing formaldehyde as before (29) and blotted onto Genescreen filters (New England Nuclear, Mass) as described by the manufacturers. Filters were prehybridised overnight in plastic bags containing $0.2 \mathrm{ml} \cdot \mathrm{cm}^{-2}$ of a solution containing $50 \%(\mathrm{v} / \mathrm{v})$ de-ionised formamide, $0.2 \%(\mathrm{w} / \mathrm{v})$ bovine serum albumin, $0.2 \%(\mathrm{w} / \mathrm{v})$ ficoll $40000,0.2 \%(\mathrm{w} / \mathrm{v})$ polyvinylpyrrolidone, $1 \%(\mathrm{w} / \mathrm{v})-\mathrm{Na}$-dodecylsul- 
R.P. Oliver \& C. Poulsen: pHvC35

$\begin{array}{llllll}10 & 20 & 30 & 40 & 50 & 60\end{array}$

AAGCTTCTCA AGCTCAAGCA TTTACTTTTC TAGTTAGAGA CCAGCGTCTT GgAGCTAATG

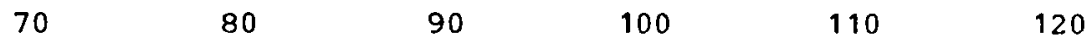

TGGGATCCGC TCAAGGACCC ACAGGTTTAG GGAAATATCT AATCCGTTCC CCAACTGGGG

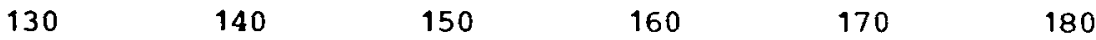

AGGTTATCTT TGGAGGGGAA ACTATGCGTT TTTGGGACCT TCGTGCTCCA TGGTTAGAAC

$190 \quad 200 \quad 210 \quad 220 \quad 230 \quad 240$

CTCTAAGGGG CCCCAACGGT TTGGACTTGA GTAGGTTGAA AAAAGACATA CAACCTTGGC

$250 \quad 260 \quad 270 \quad 280 \quad 290 \quad 300$

AAGAACGGCG CTCAGCAGAA TATATGACCC ACGCTCCTTT AGGCTCTTTA AATPCCGPGG

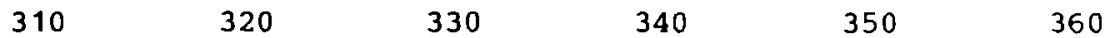

GTGGCGTAGC GACCGAGATC AATGCAGTTA ATTATGTCTC TCCTAGAAGT TGGTTATCAA

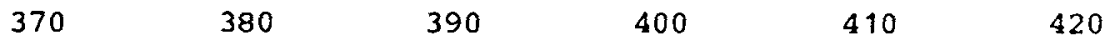

CTTCTCATTT TGTTCTAGGA TTCTTCTTTT TTGTGGGCCA TTTATGGCAT GCAGGAAGAG

$\begin{array}{rrrrrr}430 & 440 & 450 & 460 & 470 & 480\end{array}$

CCCGAGCTGC TGCAGCAGgt TTtgaAAAgG GAATCGATCG TGATTTGgAA CCTGTTCTTT

$\begin{array}{lllll}490 & 500 & 510 & 520 & 530\end{array}$

ACATGAACCC TCTTAACTAA GATTTTCTMA TTTATACCTG TTCTACTTTG TTTCTGTTCT

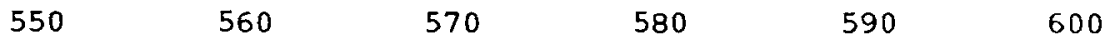

GGCTCGGTTA TTCTATCTAG CCGAGCCATT CATTCCTTTT TATGAAAGAA AGATAAGGGA

$610 \quad 620 \quad 630 \quad 640 \quad 650 \quad 660$

CAGAATAAAA AAAAATGAA GAAACAAACG TATTCAATAA GCAAAAGGAG AGAGAGgGAT

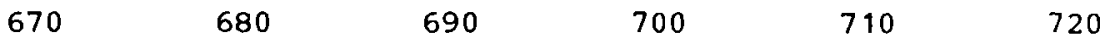

TCGAACCCTC GATAGTTCCT AGAACTATAC CGgTTTTCAA GACCGGAGCT ATCAACCACT

$\begin{array}{llllll}730 & 740 & 750 & 760 & 770 & 780\end{array}$

CAGCCATCTC TCCACCGCCT AATCCTTATT TTACTCCTAC AAATAGAACA TAGCCATATA

$\begin{array}{lllllr}790 & 800 & 810 & 820 & 830 & 840\end{array}$

AAAAATAAAA ATATTPATTA ACCTCTAGAA AGATATCAGA TACAAGTTCC TTTTCGATAT

$\begin{array}{llllll}850 & 860 & 870 & 880 & 890 & 900\end{array}$

ATCTCTGTAT ACTGTATACA CGGATACAGG ATCCGCTATA CCCGCTTGTG AAATAAAGAC

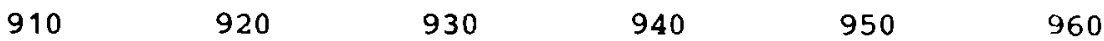

TAAATAACCT CCTCTCACCC CCATATCCAA ATAAAAAAGA GGTTAAGTAA TAAATTTTAA

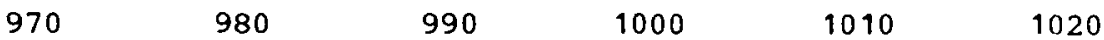

TTAAAGAGAA GAATCAATGG ATTCATGATT AAACCCCTCC TACTTCTTGT ATT"ITTTAC

$\begin{array}{lllllr}1030 & 1040 & 1050 & 1060 & 1070 & 1080\end{array}$

AATTTTGGTT AAGTGAGGGA TCAAATATGT AGTCAACTTT ATTTGATGGT AGCTTGGAGG Figure 3. DNA sequence of pHvC35. Only the 5'-3' direction is shown. 
R.P. Oliver \& C. POUlSen: pHvC35

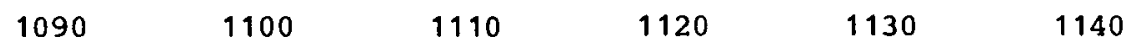

ATTAGAAATA TGACTATTGC TTTCCAATTA GCTGTTTTTG CATTAATTGC GACTTCCTCA

$1150 \quad 1160 \quad 1170 \quad 1180 \quad 1190 \quad 1200$

GTCTTAGTAA TTAGTGTACC CCTTGTATTT GCTTCTCCTG ATGGTTGGTC AAATAATAAA

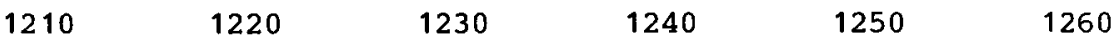

AATGTTGTAT TTTCCGGTAC ATCATTATGG ATTGGACTAG TCTTTCTCGT AGCTATTCTG

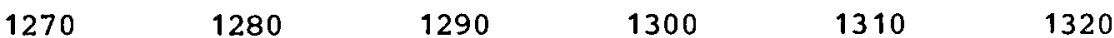

AATTCTCTCA TTTCTTAAAT TAAATTTGGT TAATATTTAG TAACCCCATA AAAAAGAAAT

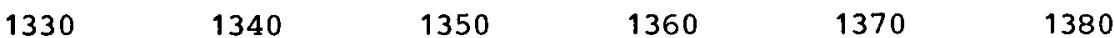

AATAAAGGCC ATTTAAAAAA TTCGAATAGT GAGACGTATT AAAACGCAAT TTGCGTTCCG

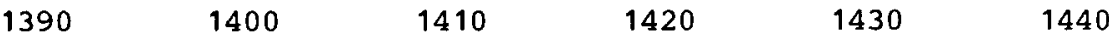

AATTGCTAGC TCTTCTCTTT CAGTATTATG AAATTCCCAT TAGAATATTC ATTGACAGAT

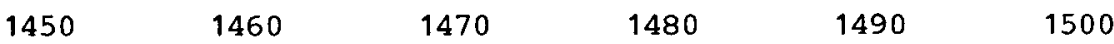

AATAAAAAAA GGAAAACTCT AATATCTAAT ATAATAGAAT AGAAAATGAA ATGAAACGGT

$1510 \quad 1520 \quad 1530 \quad 1540 \quad 1550 \quad 1560$

CGACCCAGAC ATAGACGGTC GACCCAAGCG GATATACGCT ATAAAATATA TACCGTAGCG

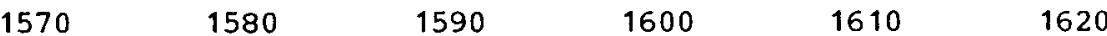

AGCGTAGTTC AATGGTAAAA CATCTCCTTG CCAAGGAGAA GATACGGGTT CGATTCCCGC

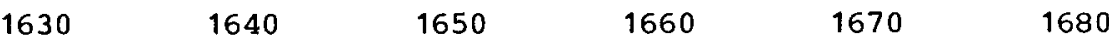

CGCTCGCCCG CTTAATTTAT CAAAGTACTA TGATAAAAGT TTAGTCTAGT TAATTGTTTA

$1690 \quad 1700 \quad 1710 \quad 1720 \quad 1730 \quad 1740$

ACTACTTATC TTAAATTAAG TATTAATTAA GTATTAGTCT AGTGCCGTAT CCCTTACTAT

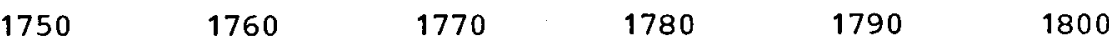

ATTTACCCTT CCTTTGCATC CCCCTCAAAA AAAGAGGGGG CTCCGGAGGC AGAAATAGAA

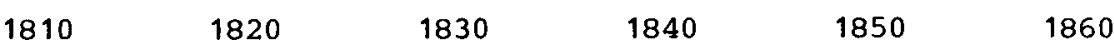

CTAGCCAACA GAGCCCCAAA ATTGGGTATT AACTGAGACA AACAACGGGC AAACTGTTTT

$\begin{array}{llllll}1870 & 1880 & 1890 & 1900 & 1910 & 1920\end{array}$

TAAAAGGAAG GGAGAGGAGA CTGTCCCTTT CATTTCATTT TTATTTTCTG CAAGGTAGGG

$\begin{array}{llllll}1930 & 1940 & 1950 & 1960 & 1970 & 1980\end{array}$

AGAAGCCTTG CGCCTTCTTT TTGTGAAGGC AAGTGGCTTC GCAAATTGCT CAATTTTGCC

$19902000 \quad 2010 \quad 2020 \quad 2030 \quad 2040$

CTCTAGgGCC CGGAACTAAA TAATAAAAAA GgGTTGGATA CGCCCCTCTA CCATATCTAG

$20502060 \quad 2070 \quad 2080 \quad 2090 \quad 2100$

AGAAATAGAA TACTCCTTTT ATAGAGACTG CTAAGTGCGG AGACGGGAAT CGAACCCGTG

$2110 \quad 2120 \quad 2130 \quad 2140 \quad 2150 \quad 2160$

ACCTCAAGGT TATGAGCCTC GTGAGCTACC AAACTGCTCT ACTCCGCTCT GTAGTACCAG 
R.P. OLIVER \& C. Poulsen: pHvC35

$\begin{array}{llllrr}2170 & 2180 & 2190 & 2200 & 2210 & 2220\end{array}$

AAACTGGTGG ACAAAAAAGG CTTGAATACA AGCCTTTAAC ATGTCTAGAC AAATAGAATA

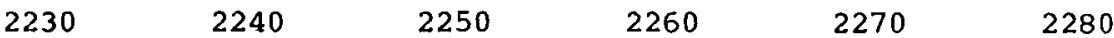

CTCCTT"TAT ACAGAATGGA GCGGGTAGCG GGAATCGAAC CCGCATCGTT AGCTTGGAAG

$2290 \quad 2300 \quad 2310 \quad 2320 \quad 2330 \quad 2340$

GCTAGGGGTT ATAGTCGACG TTGGTTGATT ATTTTMAACG TCPCTAATTC AAAACCGAAC

$2350 \quad 2360 \quad 2370 \quad 2380 \quad 2390 \quad 2400$

ATGAAATTTT GATTTCATTC GGCTCCTTTA TGGATATTCT CACCACTTAA CATCTATGTC

$2410 \quad 2420 \quad 2430 \quad 2440 \quad 2450 \quad 2460$

AGCTTTTCTA TITGAATGGA ACCAAAGCTC TCTGCTTTCT AGATGATCCT TATAGAGTAG

$2470 \quad 2480 \quad 2490 \quad 2500 \quad 2510 \quad 2520$

GAGATAGAAA TTCTATCTAA ATCCATCTAA TCTACTTACT TCGTTCCCTA ATTTCATTCA

$2530 \quad 2540 \quad 2550 \quad 2560 \quad 2570 \quad 2580$

AGAGATCCTG AGGAAAAGAA TTGGGTTTCC ACCGAGCTGA AACAATATGC GGATGGTTCT

$2590 \quad 2600 \quad 2610 \quad 2620 \quad 2630 \quad 2640$

AGTAAACCAA AACTATCGTT TPTTAGCTAT TTGGCTTCCT TATCCTTTAA CAAAAGAAGA

$2650 \quad 2660 \quad 2670 \quad 2680 \quad 2690 \quad 2700$

TTTAGTTACG ATTGGAAATC AACTTTTTTG TATCTTCATC CATAGATCCT TTACTCATAT

$2710 \quad 2720 \quad 2730 \quad 2740 \quad 2750 \quad 2760$

TTTCAAAATT GGAATACTTA AATCCAATGC AAAATTACCC TTCCCGACTC TGTACTCATA

$2770 \quad 2780 \quad 2790 \quad 2800 \quad 2810 \quad 2820$

TCATAATCCA ATTTTTATTT TGGATGCAAT TTAAATTAGT TTTTGGGTAC AAATCGCCAG

$28302840 \quad 2850 \quad 2860 \quad 2870 \quad 2880$

AATGTATATT C'TTCCTCAAT ATGCTATTGA GAGGAAACGG ATTTAATCCT TTATAAGAAC

$2890 \quad 2900 \quad 2910 \quad 2920 \quad 2930 \quad 2940$

TAAAGTTTTC ATCGGAATAT AAAAAACCTT AAGGATGCCT TAAGTATATC ATTTCAAATT

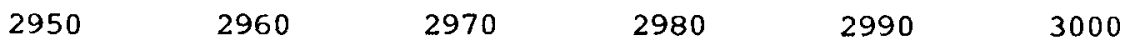

CAGTTATTAA TAGAACGAAT CACACTTTTA CCACTAAACT ATACCCGCTA CATTGTATAT

$\begin{array}{llllll}3010 & 3020 & 3030 & 3040 & 3050 & 3060\end{array}$

TATGGTATAA ATGGTACCCT TTGTCAAGGA TAGCCATTTG ACAAGGAGGC TAATTCCCCC

$\begin{array}{llllll}3070 & 3080 & 3090 & 3100 & 3110 & 3120\end{array}$

TTATTGAATC AGATGGAGAA GGTTCATGAC ACTGAGCCAT, TGGTACTTCT ACTTCGATCG

$\begin{array}{llllll}3130 & 3140 & 3150 & 3160 & 3170 & 3180\end{array}$

CGCGCCTTTA CTITAGGATT TAGATAGCCC CTCTCCCTCT GGTCTGTAAA ATAAATCTCT

$\begin{array}{llllll}3190 & 3200 & 3210 & 3220 & 3230 & 3240\end{array}$

TCTTACCCTG CTAATAGCGC CTGAACCAAA TGTATTTATT TTGATTAGGA TCCTATCCTA 
R.P. Oliver \& C. POUlSEN: pHvC35

$\begin{array}{llllll}3250 & 3260 & 3270 & 3280 & 3290 & 3300\end{array}$

TTCTACGGTT ACGACTACAA TAATCATTAT TTACTTTGCG AGGACGTAAG TGTGCCAGAC

$\begin{array}{llllll}3310 & 3320 & 3330 & 3340 & 3350 & 3360\end{array}$

TGCTAAATGG TTTATTATTT ATTCCTACAA TATAAACTAG GGGATATAGG GGGTAACACT

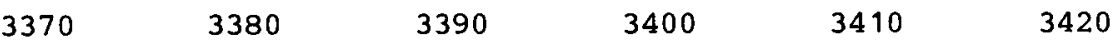

CTCCCTATAA ATTCCTTPTT TCCTTTTCTT TTTTGTCCAG AATTGAACAA AAAAGAAATT

$\begin{array}{llllrr}3430 & 3440 & 3450 & 3460 & 3470 & 3480\end{array}$

ATAGAAGATG TTTTCTTCCC CCATTAAGTC CGAGCCATAG AGTAAGAGGT GAGATGAGTT

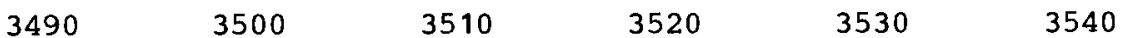

TTCCAAATTC ATCATAGACT TTCCCTATGG CTTGATAGAA GTAAGAAGCA AAGAGTTGTA

$\begin{array}{llllll}3550 & 3560 & 3570 & 3580 & 3590 & 3600\end{array}$

ACTTAAAGAG TCGTAACTTA AAGAAAAAAA CGGACAGGGC TGACAGATTT ACCTGATGTA

$\begin{array}{llllll}3610 & 3620 & 3630 & 3640 & 3650 & 3660\end{array}$

AAGAAGATCC TAAAAGTCTA TGATTAGTCG ACTCTCTCCA TTIAACACTT TCCTCTCTCT

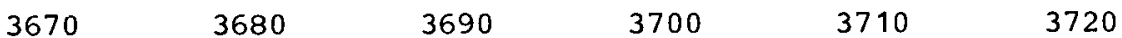

CCTTTTTTCC ACTGACTCAA TGCTAGTTTA TTAGATTCTT GTTTAAAAGA ATCAAAAAAG

$\begin{array}{llllll}3730 & 3740 & 3750 & 3760 & 3770 & 3780\end{array}$

TTCAATAGAA CTAAGAACAC ATAAAAAATA GCATAGAGGA TCAAGGCCAT TACCAAAAGT

$\begin{array}{llllll}3790 & 3800 & 3810 & 3820 & 3830 & 3840\end{array}$

TCCTCCCAAG GATCCTATCC TATTGAGTAT CTGTTCCCTG CCTTTCCCGT AGGTTAGGAA

$\begin{array}{llllll}3850 & 3860 & 3870 & 3880 & 3890 & 3900\end{array}$

ATCTTATATT TTCCATATAC CATTGAATCC TTGGGGTTCC AGAATCCGCC TATTTTACTA

$\begin{array}{llllll}3910 & 3920 & 3930 & 3940 & 3950 & 3960\end{array}$

GCCTTCGGAA ATCGGAAAAC CATGAACCAA GAAGAGTTGG GTAGTTTTCT TTCCTTAATT

$\begin{array}{llllll}3970 & 3980 & 3990 & 4000 & 4010 & 4020\end{array}$

TTATTTTGAG CTCTCAAGAT ATCAATACAT ATACAATCTA TACATAATGT CTCTCTCTAT

$4030 \quad 4040 \quad 4050 \quad 4060 \quad 4070 \quad 4080$

ATCTCBATAT ATTATATATA TATAATATGT ACATTATGCA GTAGACCCAT AATGGGAAAT

$4090 \quad 4100 \quad 4110 \quad 4120 \quad 4130 \quad 4140$

CAAAGTGGCA AATTTTTGAA TTAAATAAAA AGCCCTTTTA ACTCAGTGGT AGAGTAATGC

$\begin{array}{llllll}4150 & 4160 & 4170 & 4180 & 4190 & 4200\end{array}$

CATGGTAAGG CATAAGTCAT CGGTTCAAAT CCGATAAAGG GCTTTTTAAA TTAGTGGTAG

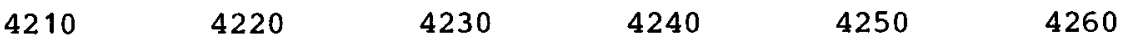

AGTAATCTCG TGCTAAGACG TAAGTCATTG GTTCGAATCT GATAGAGTAC TTTTCTACTA

$4270 \quad 4280 \quad 4290$

AATTGATTCG CTTTTTTCTT TGTTTTTGAA GCTT 


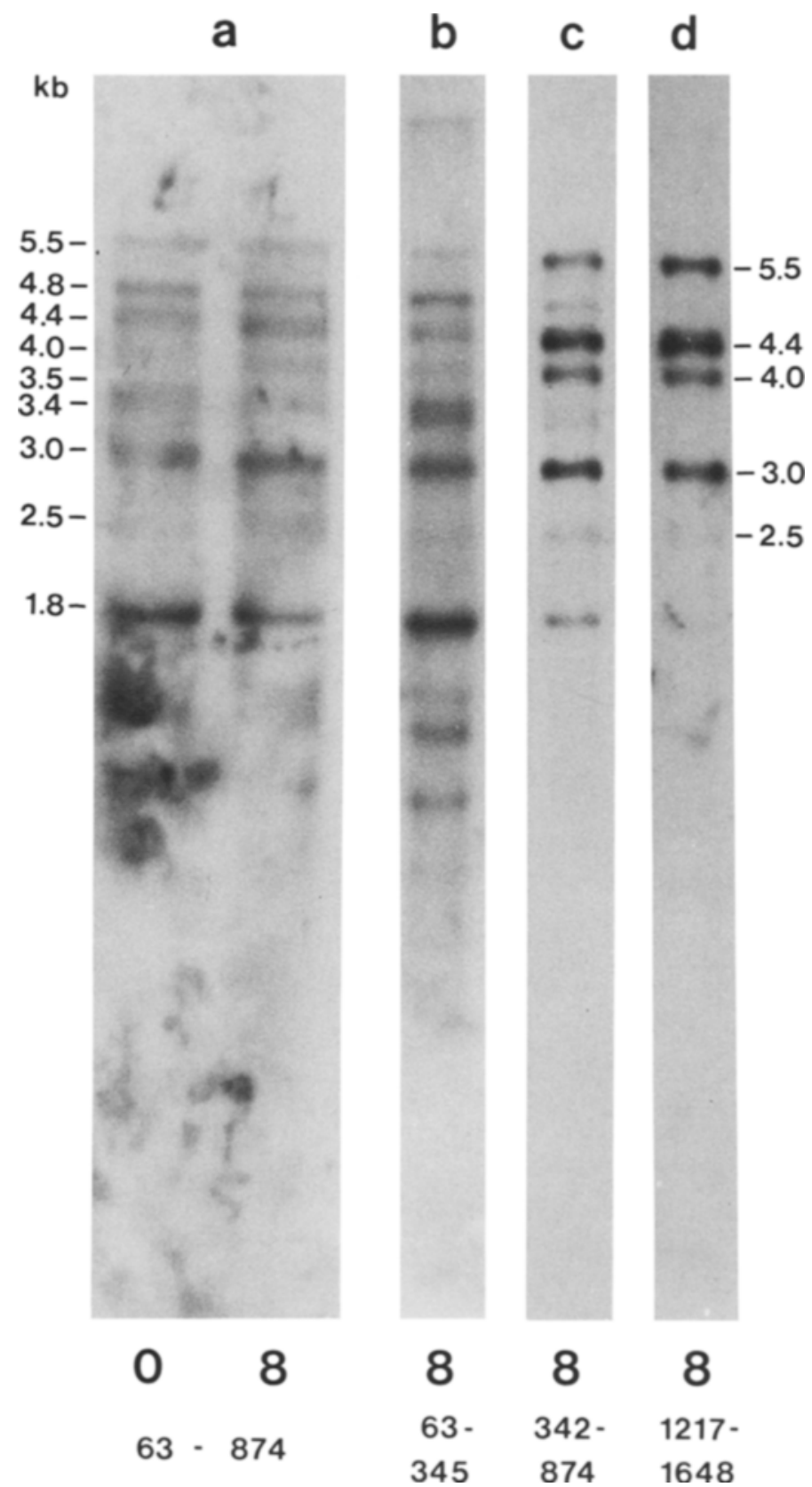

Figure 4. Northern analysis of the constitutive transcripts.

RNA from etioplasts $(0)$ and 8 -hour greened chloroplasts (8) was electrophoresed on agarose gels and blotted onto Genescreen. Four probes $(63-874,63-345,342-874$ and 1217-1648) were made radioactive and hybridised to the Genescreen filters as described in section 2.3.

phate, $0.5 \mathrm{mg} \cdot \mathrm{ml}^{-1}$ sonicated, phenol-extracted, heat-denatured salmon sperm DNA, $0.75 \mathrm{M}$ $\mathrm{NaCl}$ and $75 \mathrm{~mm}-\mathrm{Na}$-citrate at $42{ }^{\circ} \mathrm{C}$ with shaking.
Probes were prepared from M13 subclones annealed to either a sequencing primer (30) or the "hybridisation" primer (13) (both from Boehringer, Mannheim, FRG). In both cases the 


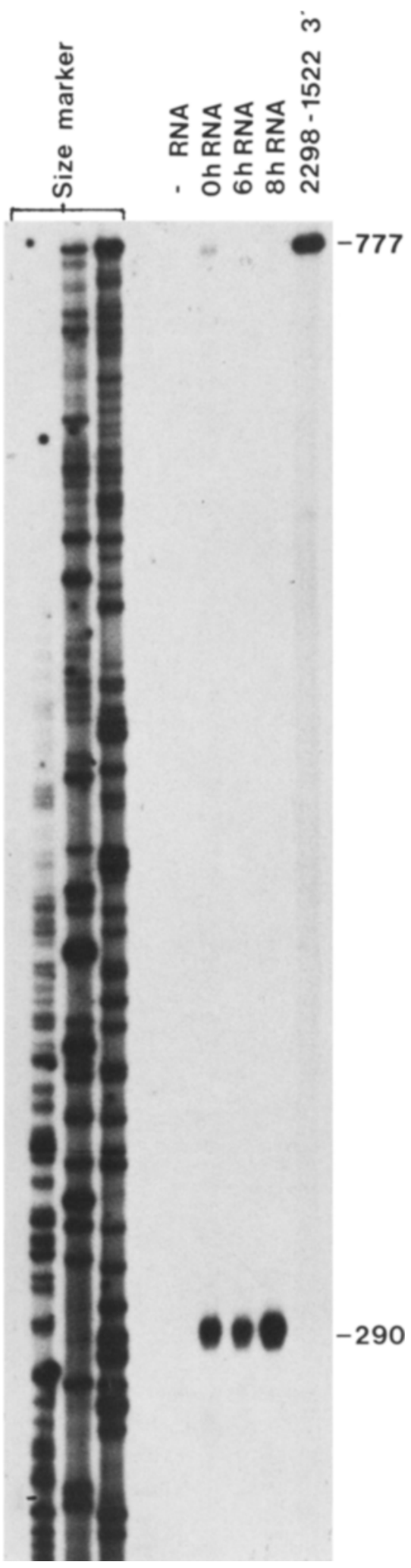

primer was extended using 0.5 units DNA polymerase (Klenow subfragment), $10-50 \mu \mathrm{Ci} \alpha^{32} \mathrm{P}$ dATP $\left(600 \mathrm{mCi} \cdot \mathrm{mmol}^{-1}\right.$, New England $\mathrm{Nu}-$ clear), $50 \mu \mathrm{M}$-dGTP, $50 \mu \mathrm{M}$-dCTP, $50 \mu \mathrm{M}$ dTTP, $50 \mathrm{~mm}-\mathrm{NaCl}$, and $10 \mathrm{~mm}-\mathrm{Tris}-\mathrm{HCl}, \mathrm{pH}$ $8.0 \mathrm{in}$ a total volume of $20 \mu \mathrm{l}$. The mixtures were incubated at either $15^{\circ} \mathrm{C}$ for $90 \mathrm{~min}$ (hybridisation primer) or room temperature for $15 \mathrm{~min}$ (sequencing primer). When using the sequencing primer, the reaction was chased for a further $15 \mathrm{~min}$ with $100 \mu \mathrm{M}$-dATP. Thereafter the double-stranded DNA was cut with HindIII (M13mp9 subclones) or EcoRI (M13mp8 subclones). Unreacted dATP was removed from both types of probe by passage through a Sephadex-G50 column equilibrated in $10 \mathrm{mM}$-Tris$\mathrm{HCl}, \mathrm{pH}$ 8.0, 1 mM-EDTA.

After removal of the prehybridisation solution from the plastic bags, the hybridisation solution (as for prehybridisation but $0.1 \mathrm{ml} \cdot \mathrm{cm}^{-2}$ solution and $250 \mu \mathrm{g} \cdot \mathrm{ml}^{-1}$ salmon sperm DNA were used) containing $10^{6}-5 \cdot 10^{6} \mathrm{cpm}$ of probe was added and shaking was continued for 40 hours. The probes produced with the sequencing primer were boiled for $5 \mathrm{~min}$ before use.

The filters were washed twice with both 0.3 $\mathrm{M}-\mathrm{NaCl}, 30 \mathrm{~mm}-\mathrm{Na}$-citrate, $0.1 \%$ (w/v) Nadodecylsulphate at room temperature and with $15 \mathrm{~mm}-\mathrm{NaCl}, 1.5 \mathrm{~mm}-\mathrm{Na}$-citrate, $0.1 \%(\mathrm{w} / \mathrm{v})$ $\mathrm{Na}$-dodecylsulphate at $50{ }^{\circ} \mathrm{C}$. The filters were vigorously shaken for $15 \mathrm{~min}$ in trays containing about $150 \mathrm{ml}$ of the solutions. Subsequently the filters were air-dried and autoradiographed. The rRNAs served as internal standards for the extrapolation of the sizes of the transcripts.

The endpoints of selected transcripts were determined by $\mathrm{S} 1$-nuclease digestion of hybrids between chloroplast RNA and radioactive single-stranded DNA probes (1). End-labelled

Figure 5. S1-mapping the 3' ends of the constitutive transcripts.

3'-end-labelled probe 2298-1522 was prepared and hybridised either to no RNA (-RNA), etioplast RNA (0h RNA), RNA from 6-hour greened chloroplasts (6 hours RNA) or RNA from 8-hour greened chloroplasts (8h RNA). Each sample was digested with S1-nuclease and electrophoresed on a $6 \%$ polyacrylamide gel. Undigested probe ( 3 '2298-1522) and a dideoxy-sequencing reaction were run as markers. 

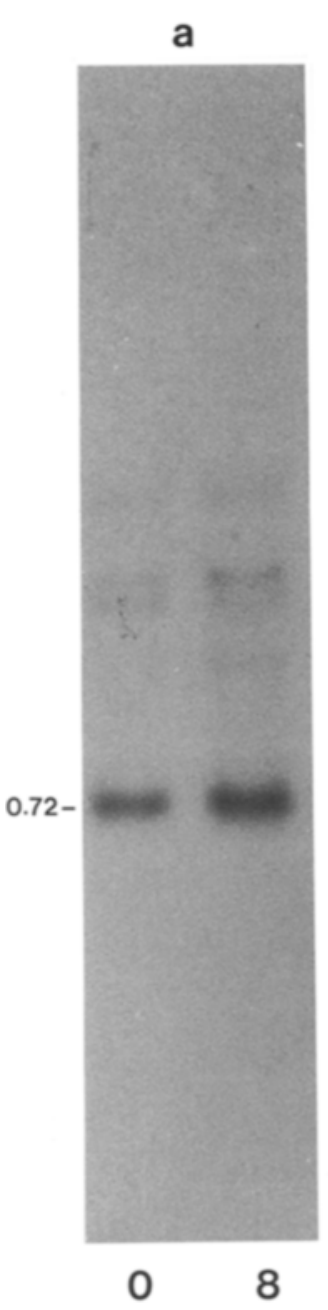

$3795-3228$ b

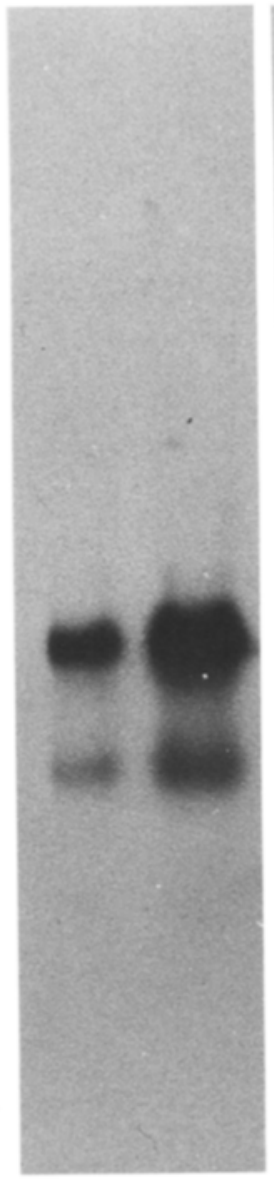

0

$3632 \cdot 2294$ c

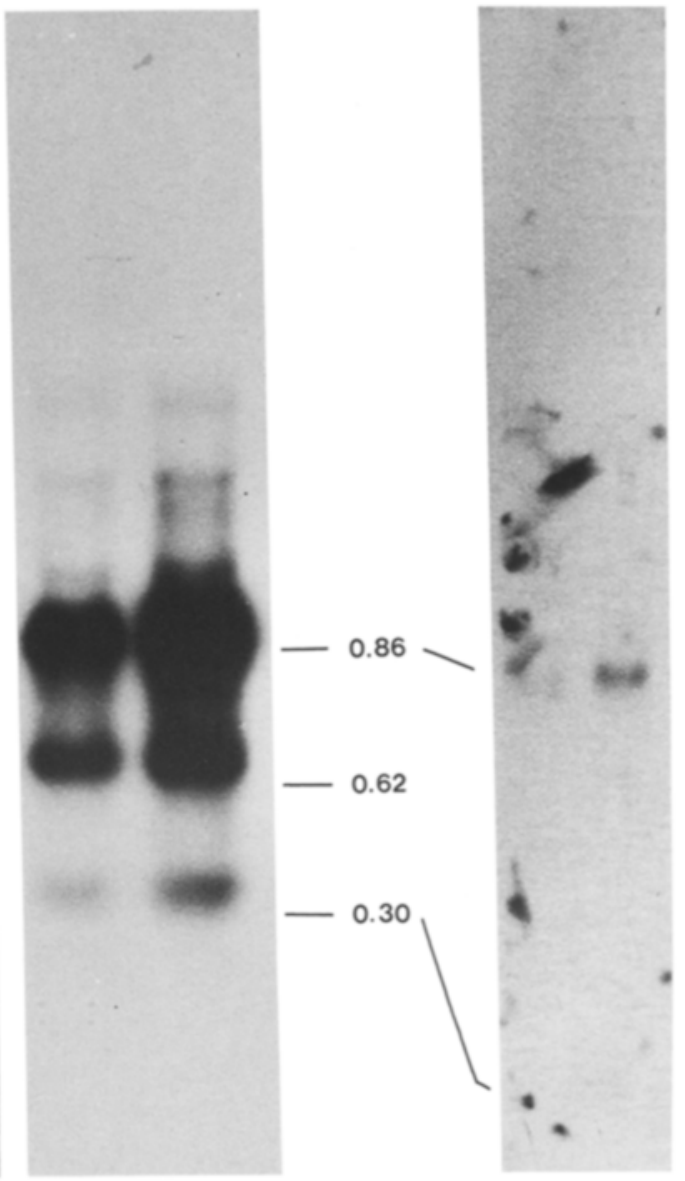

08

$2294 \cdot 1518$

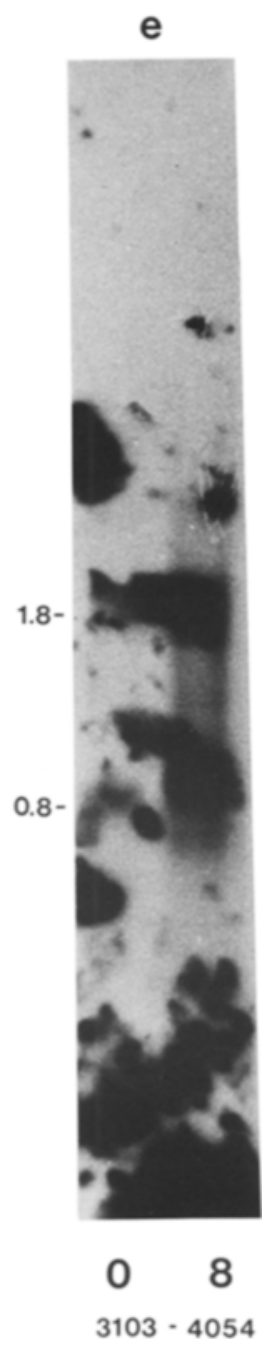

Figure 6. Northern analysis of the light-induced transcripts.

RNA was electrophoresed and blotted (2.3) and hybridised with the five indicated M13 probes. The filters $\mathrm{d}$ and $\mathrm{e}$ were obtained from a gel electrophoresed for a longer time than used for the filters $\mathrm{a}, \mathrm{b}$ and $\mathrm{c}$.

probes were prepared by digestion of $\mathrm{pHvC} 35$ with SalI, XbaI, XbaI + BamHI and SalI + Sau96-I. The fragments were labelled at the 5' end using polynucleotide kinase or at the 3' end using the fill-in reaction of the Klenow fragment of DNA polymerase (23). Double-stranded DNA was dissociated and the strands were separated on polyacrylamide gels and purified according to MAXAM and GILBERT (23). The single-stranded probes were hybridised to chloroplast RNA, digested with S1-nuclease and electrophoresed on polyacrylamide gels using a dideoxy-sequencing reaction as size-marker as before (30).

\subsection{Chemicals and enzymes}

All chemicals were of Analar grade and obtained from sources described previously (29, 30). DNA modifying enzymes were from Boehringer, Mannheim, FRG except for Sall and DNA ligase (from New England Biolabs) and 
polynucleotide kinase (from Amersham International, Bucks, UK.). All enzymes were used according to their manufacturers' instructions. Radioisotopes ( $\alpha^{32} \mathrm{P}$-dATP, $600 \mathrm{Ci} \cdot \mathrm{mmol}^{-1}$ and $\gamma^{32} \mathrm{P}$-ATP, $\left.3000 \mathrm{Ci} \cdot \mathrm{mmol}^{-1}\right)$ were from New England Nuclear, Ma., USA.

\section{OVERVIEW}

Figure 1 presents an overview of the results and conclusions of this study. The horizontal axis represents the 4294 bases of the DNA sequence of the HindIII insert of $\mathrm{pHvC} 35$. The sizes and positions of open-reading frames (green arrows), transcripts (light-blue arrows for light-induced transcripts, dark-blue for constitutive transcripts), tRNA genes (red arrows) and short-repeated sequences (black arrows) are indicated. The sequence of a partially overlapping portion of maize chloroplast DNA $(19,21)$ has been similarly summarised.

\section{RESULTS}

\subsection{DNA sequence of $\mathrm{pHvC35}$}

Figure 2 shows the location and orientation of the $4.3 \mathrm{kbp}$ HindIII fragment in the barley chloroplast genome in relation to the inverted repeats and the rbcL gene. The restriction endonuclease map of the fragment indicates the restriction fragments ligated into $\mathrm{M} 13$ vectors for sequencing. The arrows indicate the direction and extent of sequence information obtained from each subclone. In all but 4 places the sequence of both strands of the DNA has been obtained. Where not, the sequencing reactions were repeated.

The sequence obtained is shown in Figure 3. The 5'-3' direction of only one strand is shown. Locations within the sequence are referred to by quoting their inclusive coordinates. Fragments designated as having descending coordinates are from the strand complementary to the one shown. Coordinates of M13 subclones refer to the sequence complementary to their insert i.e. the sequence potentially obtained by the dideoxy-sequencing procedure.

\subsection{Transcript mapping}

\subsubsection{Constitutive transcripts}

RNA was isolated from chloroplasts, electro- phoresed on formaldehyde/agarose gels and transferred to Genescreen filters. In some experiments RNA from etioplasts was co-electrophoresed in order to detect light-induced differences in the hybridising transcripts. Radioactive probes were made using M13 subclones of pHvC35. This approach allows the position, direction and size of a transcript to be estimated. The ends of each probe used are indicated in Figure 1. By using a number of overlapping probes the ends of the transcripts were mapped with a minimum accuracy of $300 \mathrm{bp}$.

Probe 63-874 hybridised to 9 transcripts of $1.8,2.5,3,3.4,3.5,4,4.4,4.8$, and $5.5 \mathrm{~kb}$ (Figure 4a). Artefactual hybridisation associated with the rRNAs ( 1.1 to $1.9 \mathrm{~kb}$ ) has been ignored. No differences were observed between etioplast $(0)$ and chloroplast (8) RNA. As expected probe 63-345 hybridised to the same 9 transcripts with similar intensities (Figure 4b). Likewise, probe 342-874 hybridised to all 9 transcripts (Figure $4 c)$. However, in this case the hybridisation to four of the transcripts $(1.8,3.4,3.5$ and $4.8 \mathrm{~kb})$ was proportionately weaker. This indicated that the 3' ends of these four transcripts were at about position 500 (Figure 1). This was confirmed by hybridisation using probe 1217-1648 (Figure 4d) which showed hybridisation to five transcripts $(2.5,3,4,4.4$, and $5.5 \mathrm{~kb})$ without any trace of hybridisation to the other four. The same five transcripts hybridised to the large probe 869-3233 thus precluding additional large transcripts in the region beyond 1648 (data not shown)

A single-stranded 3'-end-labelled DNA probe 2298-1522 was hybridised to chloroplast RNA. After digestion with S1-nuclease, gel-electrophoresis revealed an S1-resistant fragment of $290 \pm 1$ bases (Figure 5). This indicates that the five transcripts hybridising to M13 probe 1217 1648 (Figure 4d) end close to position 1812.

\subsubsection{Light-induced transcripts}

Six light-induced transcripts were identified by Northern analysis. Judging by the relative autoradiographic intensities, each transcript was induced 3-6 fold by illumination for 8 hours.

Probe 3795-3228 (Figure 6a) hybridised to a transcript of $0.72 \mathrm{~kb}$. This transcript did not 
R.P. Oliver \& C. Poulsen: pHvC35

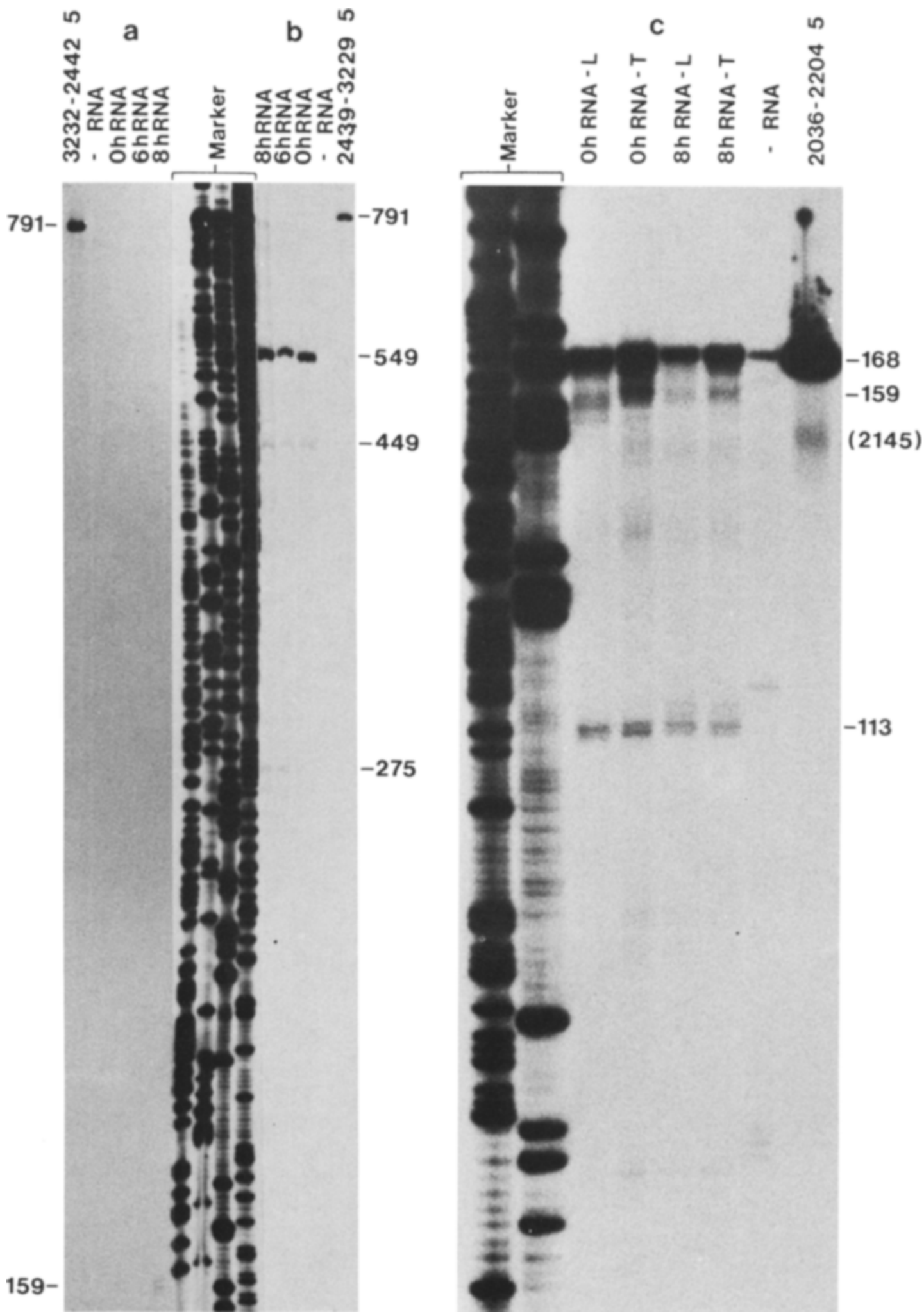




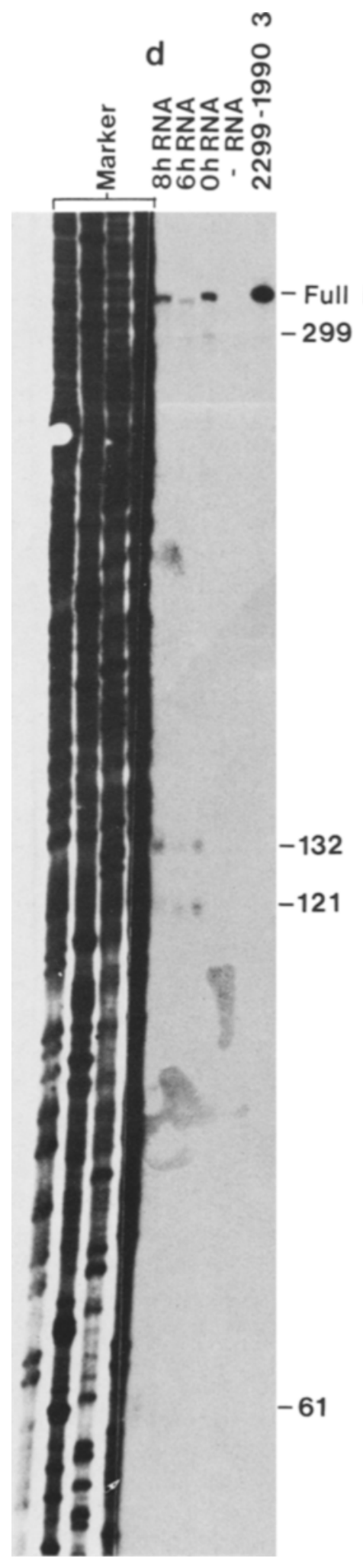

hybridise to probe $3632-2294$ (Figure 6b). This indicates that the 3' end of this transcript lies between 3632 and 3795 .

Probe 3233-1260 hybridised very strongly to transcripts of 0.62 and $0.86 \mathrm{~kb}$ and weakly to a transcript of $0.3 \mathrm{~kb}$ (Figure 6c). Artefactual hybridisation which appears to be associated with the rRNAs has been ignored. Probe 3632 2294 (Figure 6b) hybridised only to the 0.62 and 0.86 kb transcripts. Probe $2294-1518$ hybridised only to the $0.86 \mathrm{~kb}$ transcripts and weakly to the $0.3 \mathrm{~kb}$ transcript (Figure $6 \mathrm{c}$ ). The autoradiograms shown in Figures $6 \mathrm{~d}$ and $6 \mathrm{e}$ resulted from an agarose gel that was electrophoresed for longer than normal. Hence the $0.3 \mathrm{~kb}$ transcript is much more diffuse than in Figure 6c. Taken together these results indicate that the $0.62 \mathrm{~kb}$ transcript fell between 3228 and 2294 ; the $0.3 \mathrm{~kb}$ transcript between 2294 and 1518 ; and the 0.86 between 3228 and 1518 (Figure 1).

Probe 3103-4054 hybridised to two transcripts of 1.8 and $0.8 \mathrm{~kb}$ (Figure 6e). There is a very heavy background in this autoradiogram which obscures the bands. Nevertheless, the presence of transcripts is supported by results of S1-nuclease analysis (Figure $7 \mathrm{a}$ ). These transcripts were not mapped further by Northern analysis. Probes $1265-869$ and $874-63$ failed to hybridise to plastid RNA (data not shown).

The ends of some of the light-induced transcripts were mapped further using the BerkSharp technique (Figure 7). Hybridisation of 5'-end-labelled 3232-2442 to plastid RNA samples produced an S1-nuclease-resistant molecule of $159 \pm 1$ bases (Figure 7a). This indicates that either or both of the 1.8 and $0.8 \mathrm{~kb}$ tran-

Figure 7. S1-mapping the ends of light-induced transcripts.

a) 5' end-labelled $3232-2442$, b) 5 ' end-labelled 2439-3229, c) 5' end-labelled 2036-2204, or d) 3' end-labelled 2299-1990 were hybridised to plastid RNA samples, digested with S1-nuclease and electrophoresed on polyacrylamide as described (2.3). 5, end-labelled 2036-2204 (c) was hybridised to etioplast or to chloroplast RNA prepared either by centrifugation through $\mathrm{CsCl}(\mathrm{O}$ h-RNA-L, 8 h-RNA-L) or by direct phenol-extraction of plastids (O h-RNA-T, 8 $h$-RNA-T) and treated as before. 

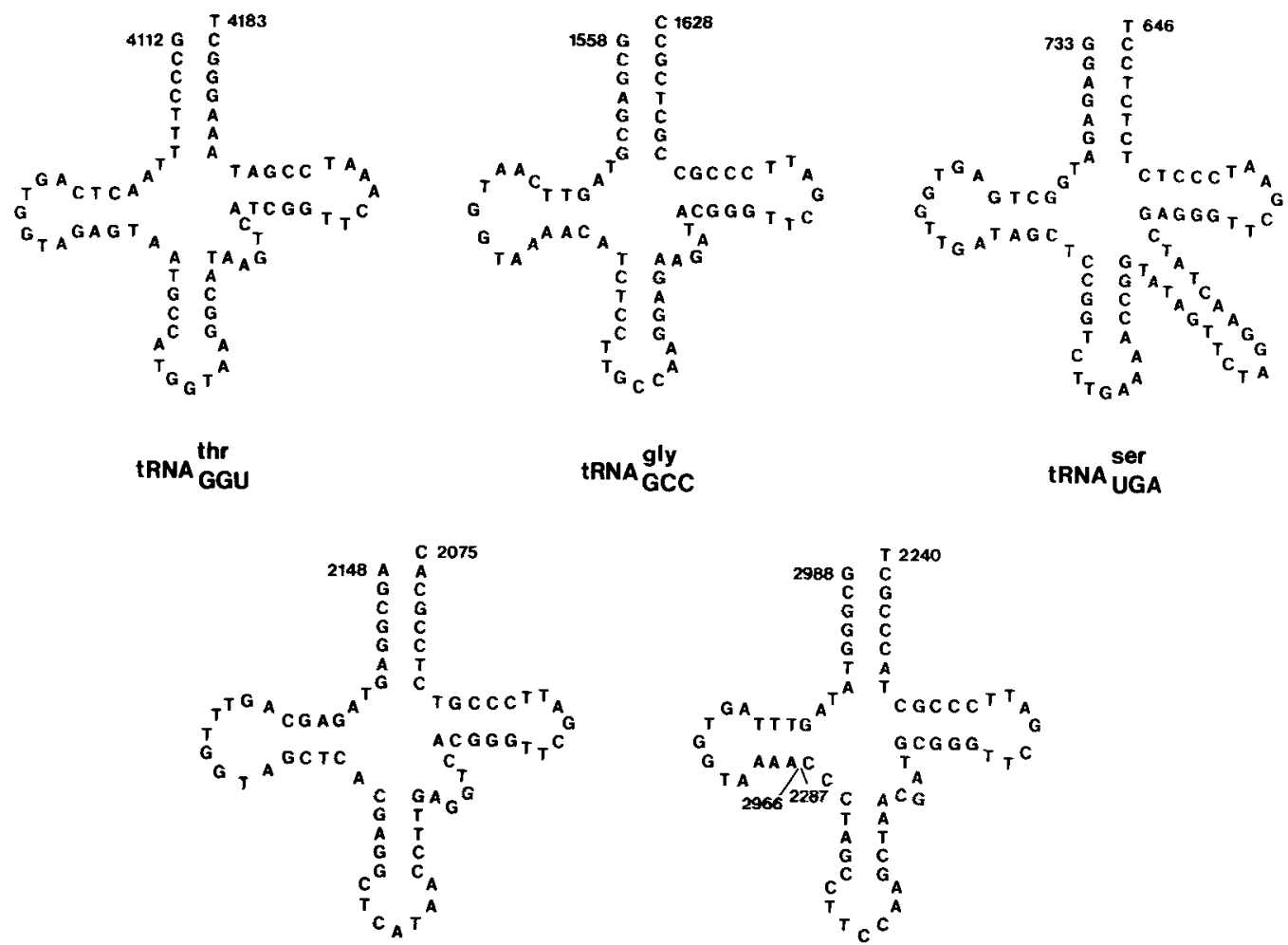

$$
\text { tRNA }{ }^{\text {f-met }}
$$

$$
\text { tRNA } \underset{\text { GCC }}{\text { gly }}
$$$$
\text { tRNA } \stackrel{\text { ser }}{\text { UGA }}
$$

Figure 8 . The non-coding strand of five putative tRNA genes folded into the cloverleaf structures. The numbers are the sequence coordinates.

scripts (Figure 6e) start at about position 3073 Judging by the autoradiographic intensity, the abundance of this (these) transcripts is low. Furthermore, RNA from 8 hour-greened chloroplasts protected significantly more of this fragment than did RNA from 6 hour-greened chloroplasts or from etioplasts. This confirms the result of the Northern analysis (Figure 6e) suggesting that the transcript was markedly light-induced.

Hybridisation of 5'-end-labelled 2439-3229 revealed a major S1-resistant fragment of $549 \pm 3$ bases together with weaker labelled fragments of $449 \pm 3$ and of $275 \pm 2$ bases (Figure $7 b$ ). This indicates start sites for transcripts at $2988 \pm 3,2888 \pm 3$, and $2714 \pm 2$. Equal quantities of DNA probe were protected by each RNA sample. As Northern analysis (Figure 6c) had indicated that these transcripts were light-in- duced, it is apparent that, in molar terms, there was excess transcript over DNA-probe during hybridisation, even when using etioplast RNA. This serves to confirm the remarkable abundance of these transcripts.

Using 5'-end-labelled 2036-2204 S1-resistant fragments of $113 \pm 1$ and $159 \pm 2$ bases were produced (Figure $7 \mathrm{c}$ ). This indicates that the start of the $0.3 \mathrm{~kb}$ transcripts may be at about 2150 or 2195 . No significant differences were observed when using RNA prepared without the $\mathrm{CsCl}$-cushion and thus including small mol. wt. RNA.

A similarly complex picture emerged from the hybridisation of 3'-end-labelled 1990-2299 to plastid RNA (Figure 7d). Protected fragments of $61 \pm 1,121 \pm 1,132 \pm 1$, and $299 \pm 1$ places 3' ends of transcripts at about 2238, 2178, 2167 and 2000 . Some of the probe was protected along 
a

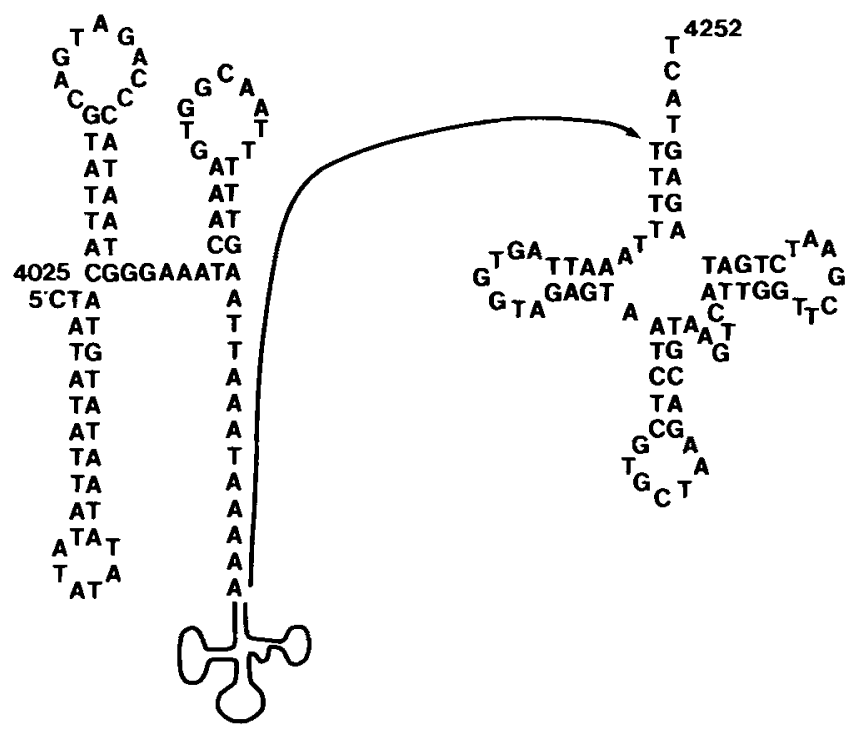

b

Figure 9. a) Possible secondary structure of the flanking regions of the $\operatorname{trnT}$ locus.

b) Possible secondary structure of the 3' end of the tRNA ${ }^{\text {Gily }}$-UCC intron sharing similar features to the group 2 introns of MICHEL and DuJON (25). Small case letters are bases altered in the corresponding tobacco sequence (9).

its full length indicating transcripts extending past 1990.

\section{DISCUSSION}

\subsection{Transfer RNA genes}

Advantage was taken of two conserved features to search by eye and by computer for putative tRNA genes. These were 5 bp inverted repeats separated by a loop of 7 bases as found in the aminoacyl- and T $\Psi \mathrm{C}$-arms and the sequence GTTCPuA found also in the TYCarm. Five putative tRNA genes were found. The cloverleaf structures of the non-coding DNA strand are shown in Figure 8. The terminal 3' CCA sequence was not found in any of the genes.

\subsection{1. $\operatorname{trn} T-G G U$}

The non-coding strand of a tRNA gene extends from 4112-4183. Judging by the anticodon, GGT, the gene codes for a threonine tRNA. The predicted length of the tRNA including the 3' CCA is $75 \mathrm{~b}$. The corresponding trnT-GGU genes from spinach and Vicia faba differ in only four places $(15,16,22)$. TA base pairs in the barley aminoacyl- and anticodonstems are replaced with GC base pairs.

KASHDAN and DUDOCK (15) noted an ORF on the strand complementary to the tRNA gene in spinach. The ATG start codon was preceeded by a Shine-Dalgarno sequence. Neither the start codon nor the Shine-Dalgarno sequence is conserved in barley. This throws doubt on the significance of the spinach ORF.

There is very little homology between the flanking regions of the $\operatorname{trn} \mathrm{T}$ gene in Vicia faba, spinach and barley. The barley upstream sequence can, however, form a large secondary structure which may act as a transcript processing site (Figure 9a). The downstream region can be folded into a cloverleaf structure which has many similarities to a tRNA gene, e.g. the sequence GGT in the D-loop and GTTCGAATC in the T $\Psi \mathrm{C}$ loop. A serine anticodon, GCT, is found. As there are a total of 7 non-Watson/Crick base pairs and an incomplete amino-acyl stem, this sequence is classified as a pseudo-tRNA gene. It is the first such gene described in higher plants. It may 
-35 box

-10 box

$== \pm=$

TTGTCAAATG GCTATCCTTG ACAAAGGGTA CCATTTATAC CATAATATAC AATGTAGCGG

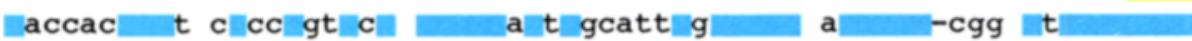

$====5$, exon $========$

GTATAGTTTA GTGGTAAAAg TGTGATTCGT TCTATTAATA ACTGAATTTG AAATGATATA

2925

CTTAAGGCAT CCTTAAGGTT TTTTATATTC CGATGAAAAC TTTAGTTCTT ATAAAGGATT

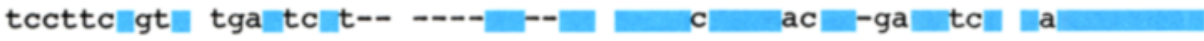

AAATCCGTTT CCTCTCAATA GCATATTGAG GAAGAATATA CATTCTGGCG ATTTGTACCC

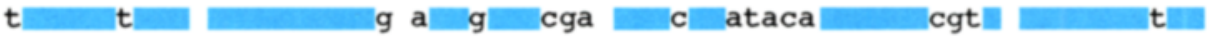

AAAAACTAAT TTAAATTGCA TCCAAAATAA AAATTGGATT ATGATATGAG TACAGAGTCG

GGAAGGGTA TTTTGCATTG GATTTAAGTA TTCCAATTTT GAAAATATGA GTAAAGGATC

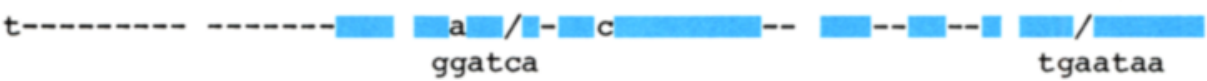

TATGGATGAA GATACAAAAA AGTTGATTTC CAATCGTAAC TAAATCTTCT TTTGTTAAAG

GATAAGGAAG CCAAATAGCT AAAAAACGAT AGTTTTGGTT TACTAGAACC ATCCGCATAT

ACGAAGTAAG TAGATTAGAT GGATTTAGAT AGAATTTCTA TCTCCTACTC TATAAGGATC

ATCTAGAAA CAGAGAGCTT TGGTTCCATT CAAATAGAAA AgCTGACATA GATGTTAaGT

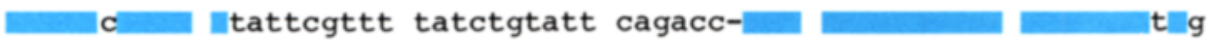

$$
\text { gtagaattct ttttttttt cgaatttggt tcacatctta gatctataaa }
$$

GGTGAGAATA TCCATAAAGG AgCCGAATGA AATCAAAATT TCATGTTCGG TTTTGAATTA ttgactcatc 
Figure 10. Homology between the barley (upper case letters) and tobacco (lower case) DNA sequence in the region of the intron-containing $t r n G-U C C$ gene. Blue = unaltered bases. Yellow = exon sequence. The "-35 box" and "-10 box" promotor sequences are indicated. Dashes (- - -) represent deletions in the tobacco sequence. Insertions are represented by /. The sequence beneath / replaces the base above.

have arisen from duplication of the adjacent threonine tRNA gene with which it shares much sequence homology.

\subsection{2. $\operatorname{trn} G-G C C$}

The non-coding strand of a second tRNA gene extends from 1558-1628. Judging by the anticodon sequence, $\mathrm{GCC}$, it is a glycine tRNA gene. The predicted length of the mature RNA is 74 bases. The Euglena gracilis genes trnG-GCC and trnG-UCC both differ in 28 places $(12,14)$. The two Euglena genes form parts of tRNA geneclusters, so it is not surprising to find no significant homology in the flanking regions with barley.

\subsection{3. $\operatorname{trn} S-U G A$}

The non-coding strand of a third tRNA gene extends from 733-646. Judging by the anticodon sequence, UGA, the gene codes for a serine tRNA. The size of the mature tRNA is 91 nucleotides. The sequence of the gene is identical to the corresponding trnS-UGA from maize (21). There is a high homology in the flanking regions (see Figure 12). However, the sequence thought by KREBBERS et al. to be homologous to bacterial promoters is not totally conserved.

\subsection{4. $\operatorname{trnfM}$}

The non-coding strand of a fourth tRNA gene extends from 2148 to 2075 . Judging by its anticodon sequence, CAU, it is a methionine tRNA gene. The mature tRNA would be 77 nucleotides in length. The tRNA is predicted to be an initiator tRNA because of its homology to the Phaseolus vulgaris (5), spinach (4) and Euglena (14) initiator tRNAs. The putative barley tRNA-fmet differs from the spinach $t R N A$ at 8 places, from the Phaseolus tRNA at 10 places and from the Euglena tRNA at 16 places. In contrast, the sequence of elongator methio- nine tRNAs from Euglena, spinach and barley are different in 29,41 and 43 positions, respectively $(12,28,46)$. Thus, the barley gene described herein shows significantly greater homology to initiator than to elongator tRNA-mets.

The barley sequence shares with the Phaseolus, spinach and Euglena initiator tRNAs two characteristics of prokaryotic initiator tRNAs: the first nucleotide cannot base-pair and the

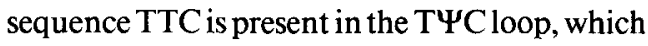
in eukaryotic initiator TRNA generally has the sequence ATC instead. However, the A57 following the TTC, which is normally found in prokaryotic initiator TRNAs, is replaced by a $\mathrm{G}$ as in many eukaryotes. Thus, the barley fmet tRNA shows both prokaryotic and eukaryotic features.

The Euglena gene is part of a tRNA cluster. There is therefore no likelihood of homology with barley in the flanking regions. The structure of the tobacco gene has been reported in abstract form $(40)$.

\subsection{5. $\operatorname{trnG}-U C C$}

The sequence 5'GCGGGTTCGATTCCCGC was found at positions 2264-2248. Although the sequence contains the conserved features of a T $\Psi \mathrm{C}$ arm, a complete tRNA sequence could not be deduced from the flanking regions. A search was made for a sequence complementary to the 3' half of the putative amino-acyl stem, 2247-TACCCGC-2241, and was found at 29882982. Starting with this aminoacyl stem and the

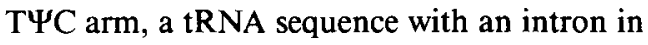
the D-stem was deduced. The length of the mature RNA is predicted to be 74 bases (29882966, 2287-2240). Judging by the anticodon sequence, UCC, it is a glycine tRNA. DENO and SUGIURA (9) have recently described a similar gene in tobacco plastid DNA. The sequence of the mature tRNAs are identical. They differ in 22 places from the trnG-GCC gene 


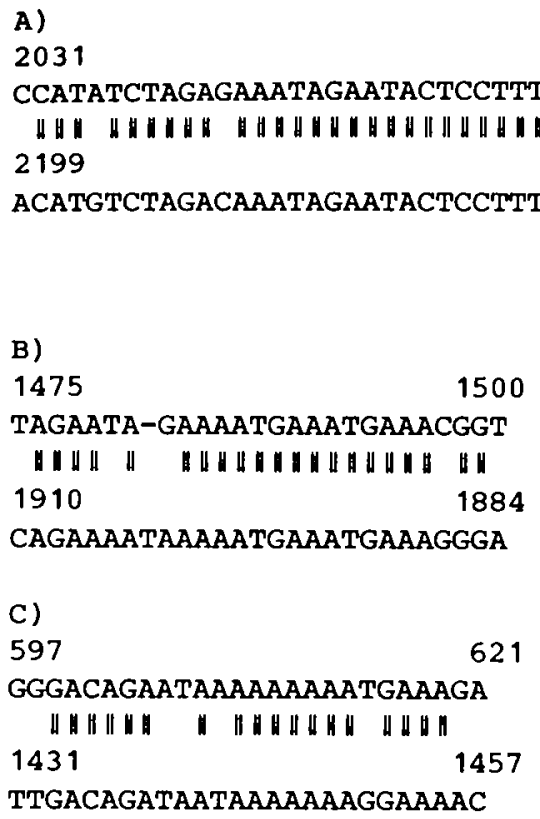

$========$ tRNA f $^{\text {met }}=======2099$

TGCGG--AGACGGGAATCGAACCCGTG

|| || | | | | || || | | | | | | || || | || | | | || || || | | $=======t_{\mathrm{RNA}} g \mathrm{l}_{\mathrm{GGA}======2265}$ AGCGGGTAG-CGGGAATCGAACCCGCA | | | | | | | | || || || | | | | | | | | | | | | || | | | ||

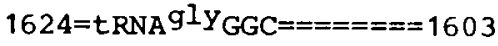
AGCGG-----CGGGAATCGAACCCGTA

D) $3528 \quad 3550$

GCAAAGAGTTGTAACTTAAAGAG

|| || | | | | | | || | | | || | | | | | | | | || | | |

$3543 \quad 3565$

TTAAAGAGTCGTAACTTAAAGAA

E)

$$
\begin{aligned}
& 641=\text { tRNA } \\
& \text { GCAAAAGGAGAGAGAGGA } \\
& \text { | || || || || || || || || | } \\
& 3668 \text { | } \\
& \text { AAAAAAGGAGAGAGAGGA }
\end{aligned}
$$

Figure 11. Five examples of tandem or inverted repeated sequences. The symbol II indicates identity between the sequences.

described above and in 21 places from a Euglena trnG-UCC (12).

The most unusual feature of this tRNA gene is the presence of an intron. Introns have been found in genes for 5 chloroplast tRNAs: alanine, isoleucine, leucine, valine as well as glycine $(8$, $10,17,21,39,41,46)$. The introns of the first four are in the anticodon loop, 3' to the anticodon. In contrast, the trnG genes from barley and tobacco both have the intron between bases 24 and 25 in the D-stem. The tobacco intron is $691 \mathrm{bp}$ and is aligned for maximum homology with the 677 bp barley intron in Figure 10. The introns are identical for the first 17 and the last 13 bases. There are only 6 changes in the last 87 bases of the introns. There are also long identical stretches in the middle of the intron. The sequence CCA is found immediately downstream of the predicted end of the 3' exon. Since only one of these bases is conserved in tobacco it is likely that the 3' CCA of the mature tRNA is added posttranscriptionally as in all other plastid tRNAs. An ORF in the complementary strand in tobacco is not, however, conserved. The likely significance of this ORF is thus diminished.
In a study of intron/exon boundary sequences in the Euglena rbcL gene, Kol.1.:R et al. (18) proposed consensus rules for these junctions. The 5' junction consensus is $G_{c}^{\prime} G_{c}^{\prime} G$ and the 3 ' consensus is TTAPuTTTTAT. The glycine intron described here obeys the 5 ' consensus (GTGTG) but not the consensus at the 3' junction (CGTCGACTATAAC). The tobacco and barley valine 5 ' junctions (CGCGC) may also fit the consensus but the exact splice site is unknown. The seven other tRNA intron junctions do not fit the consensus. MiCHEL and Dujox have studied the potential secondary structures of the introns of genes from lower eukaryotes, mitochondria and chloroplasts (25). They classified the introns into two classes on the basis of shared features. Two stem and loop structures near the $3^{\prime}$ end of the intron are similar to structures found in group 2 introns (Figure 9b). It is interesting to note that two of the bases of this sequence which are altered in tobacco cause the replacement of a TA base pair with a GC base pair. Thus, substitutions in the primary structure have conserved the putative secondary structure. 


\subsubsection{Expression of the $t R N A$ genes}

Are the five tRNA genes expressed? This question has not been directly addressed. This would require the demonstration that the mature tRNAs hybridise specifically to the genes. Hybridisation of individually identified tRNA species to plastid DNA has been performed in a number of plants (43). For comparison with barley, the most relevant species is maize (37).

The physical maps of maize and barley plastid DNA are essentially colinear (29), so gene locations are likely to be identical. Two serine isoacceptors were found to hybridise to a Sall/ BamHI fragment corresponding to the barley fragment extending from 1499 to $4.6 \mathrm{~kb}$ nearer the proximal inverted repeat. A threonine tRNA was found to hybridise to a Sall/BamHI fragment corresponding to the barley fragment extending from 2294 to $4.4 \mathrm{~kb}$ away from the proximal inverted repeat. As the serine tRNA gene was found at 733-646 and the threonine gene at $4112-4183$ there is good evidence that these tRNA genes are expressed.

In contrast, initiator methionine and glycine tRNAs did not hybridise to the position in maize. This should not, however, be taken as definitive evidence that the two glycine and the methionine $t R N A$ genes are not expressed. The technical problems associated with the purification and identification of tRNAs are such that no isoacceptor for glutamate, for example, has been mapped using these techniques (8).

As will be detailed below, it is clear that four of the tRNA genes are colinear with large RNA species. The exception is the serine tRNA gene. Establishing that these large RNAs are definitely processed into active tRNAs will require further study. The failure to detect a transcript which may be a precursor of the serine tRNA may be because the transcript is either rare or small ( $<300 \mathrm{bp}$ ). Small molecules are likely to be lost during purification of the RNA or during transfer to Genescreen.

\subsection{Repeated sequences}

Heterogeneity between chloroplast genomes of different higher plants exists on two levels. Chloroplast genomes of plants from different families differ as a result of large (up to $50 \mathrm{kbp}$ ) inversions and deletions (27). Within genera the genomes' structures are very similar, differences being limited to small ( $\mathrm{up}$ to $2 \mathrm{kbp}$ ) inversions and deletions $(3,11,42)$.

The chloroplast genomes of the grasses (barley, wheat, maize) may be regarded as the ancestral higher-plant plastid genome (27). Their closest neighbours (tobacco, spinach) differ as a result of inversion of a ca. $22 \mathrm{kbp}$ fragment extending in barley from about coordinate 70 to 92 (Figure 2). This latter site is within the fragment studied. Detailed restriction patterns have been determined for several members of the three genera, Triticum (3), Oenothera (11) and Nicotiana (42). Differences between members of the Oenothera spp. are placed randomly around the genome. In contrast, the differences between wheat spp. and between tobacco spp. are both localised in discrete regions. In both cases the region homologous to the region studied here in barley was frequently altered. TASSOPULU and KUNG (42) refer to this area as a recombination hot-spot.

Thus, both the small-scale differences within genera and the large-scale inversion distinguishing the grasses from tobacco and spinach involve the region studied in barley. Therefore, a search was made for repeated sequences which might have resulted in or from recombinations. The five largest repeats are shown in Figure 11 (see also Figure 1). Repeat $A$ has two tandem members with 57 of the 62 bases conserved (allowing two inserts to maximise homology) and one inverted member with 20 bases conserved. The 3' ends of three trn genes (fmet, G-UCC and G-GCC) make up part of the sequences. The homology may suggest that the tRNAs evolved after gene-duplication events. Four other repeats ( 21 out of 25,18 out of 22 , 19 out of 20 and all 15 bases conserved) were noted. Two are inverted and two are tandem. As it may be calculated that a $15 \mathrm{bp}$ repeat would be expected every $10^{9}$ bases, the frequency with which these sequences have been found in a $4294 \mathrm{bp}$ sequence suggests a fundamental role. The presence of the long tandem repeats opens up the possibility of inserting foreign DNA at these sites by homologous recombination when transformation of the chloroplast is achieved. 
AAGCTTCTCA AGCTCAAGCA TTTACTTTTC TAGTTAGAGA CCAGCGTCTT GGAGCTAATG
A S Q

\begin{abstract}
A $Q$
\end{abstract}
F T F

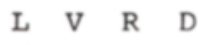
$\begin{array}{lllll}\text { L } & G & A & \mathrm{~N}\end{array}$ Q

TGGGATCCGC TCAAGGACCC ACAGGTTTAG GGAAATATCT AATCCGTTCC CCAACTGGGG $\begin{array}{lllllllllllllllllllll}V & G & S & A & Q & G & P & T & G & \text { L } & G & K & Y & \text { L } & \text { I } & \text { R } & \text { S } & \text { P } & \text { T } & G\end{array}$

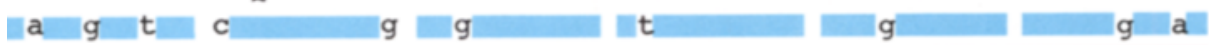
a

AGGTTATCTT TGGAGGGGA ACTATGCGTT TTTGGGACCT TCGTGCTCCA TGGTTAGAAC $\begin{array}{llllllllllllllllllllll} & \text { E } & V & I & F & G & G & E & \text { T } & \text { M } & \text { R } & \text { F } & \text { W } & \text { D } & \text { L } & \text { R } & \text { A } & \text { P } & \text { W } & \text { L } & \text { E }\end{array}$ rang CTCTAAGGG CCCCAACGGT TTGGACTTGA GTAGGTTGAA AAAAGACATA CAACCTTGGC $\begin{array}{lllllllllllllllllllll}P & \text { L } & \text { R } & G & \text { P } & \text { N } & G & \text { L } & \text { D } & \text { L } & \text { S } & \text { R } & \text { L } & \text { K } & \text { K } & \text { D } & \text { I } & \text { \& } & \text { P } & \text { W }\end{array}$

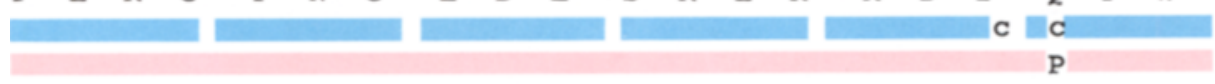
AAGAACGGCG CTCAGCAGA TATATGACCC ACGCTCCTTT AGGCTCTTTA AATTCCGTGG

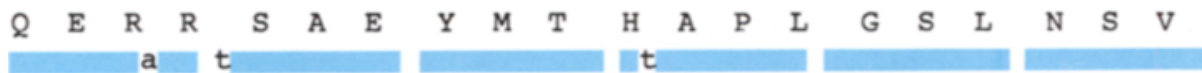
rat GTGGCGTAGC GACCGAGATC AATGCAGTTA ATTATGTCTC TCCTAGAAGT TGGTTATCAA

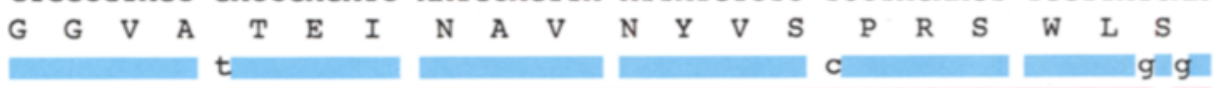
Dat CTTCTCATTT TGTTCTAGGA TTCTTCTTTT TTGTGGGCCA TTTATGGCAT GCAGGAAGA $\begin{array}{lllllllllllllllllllll}\text { T } & \text { S } & \text { H } & \text { F } & \text { V } & \text { L } & G & \text { F } & \text { F } & \text { F } & \text { F } & \text { V } & \text { G } & \text { H } & \text { L } & \text { W } & \text { H } & \text { A } & G & \text { R }\end{array}$ IC C CCCGAGCTGC TGCAGCAGGT TTTGAAAAG GAATCGATCG TGATTTGGA CCTGTTCTTT $\begin{array}{lllllllllllllllllllll}A & R & A & A & A & A & G & F & E & K & G & I & D & R & D & \text { L } & E & \text { P } & \text { V } & \text { L }\end{array}$

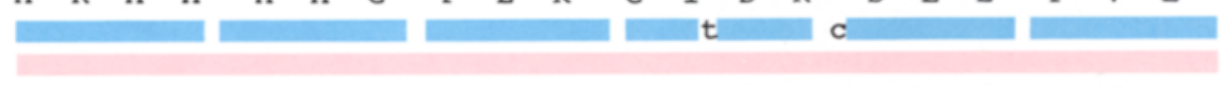
ACATGAACCC TCTTAACTAA GATTTTCTTA TTTATACCTG TTCTACTTTG TTTCTGTTCT $\begin{array}{lllllll}\mathrm{Y} & \mathrm{M} & \mathrm{N} & \mathrm{P} & \mathrm{L} & \mathrm{N} & +\end{array}$

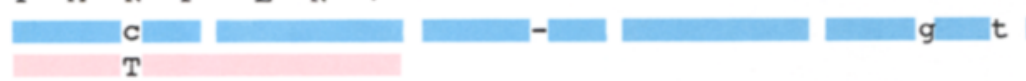

GGCTCGGTTA TTCTATCTAG CCGAGCCATT CATTCCTTTT TATGAAAGA AGATAAGGGA
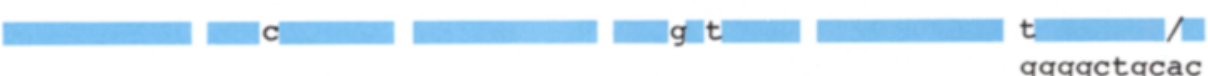

ggggctgcac

CAGAATAAAA AAAAATGAAA GAAACAAACG TATTCAATAA GCAAAAgGag AGAGAGgGaT TCCTC TCTCTCCCTA 600

Barley

Amino acid

Maize

Maize amino acid

120

180

240

300

360

420

480

540

tRNA ser 
TCGAACCCTC GATAGTTCCT AGAACTATAC CGGTTTTCAA GACCGGAGCT ATCAACCACT AGCTTGGGA CTATCAAGGA TCTTGATATG GCCAAAAGT CTGGCCTCGA TAGTTGGTGA

CAGCCATCTC TCCACCGCCT AATCCTTATT TTACTCCTAC AAATAGAACA TAGCCATATA GTCGGTAGAG AGG

$\mathrm{a} \quad \mathrm{c}=\mathrm{c}=\mathrm{t}=\mathrm{t}$

AAAAATAAA ATATTTATTA ACCTCTAGAa AgAtatcaga TACAAGTTCC TTTTCGATAT

840

tgatct actaactcat

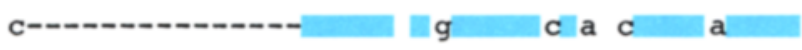

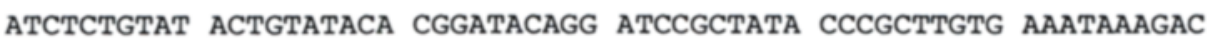

900

TAAATAACCT CCTCTCACCC CCATATCCAA ATAAAAAAGA GGTTAagtAa TAAATTTTAA

c $=\mathrm{a}=\mathrm{g}$

TTAAAGAGA GAATCAATG ATTCATGATT AAACCCCTCC TACTTCTTGT ATTTTTTTAC

1020

$-\mathbf{a}$

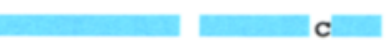

ca

AATTTTGGTT AAGTGAGGGA TCAAATATGT AGTCAACTTT ATTTGATGGT AGCTTGGAGG

1080

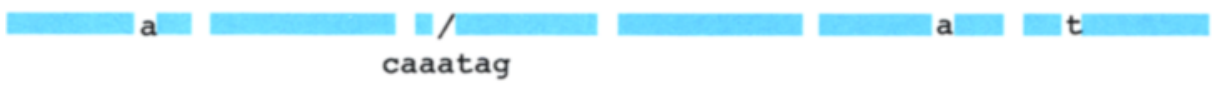

ATTAGAAATA TGACTATTGC TTTCCAATTA GCTGTTTTTG CATTAATTGC GACTTCCTCA

GTCTTAGTAA TTAGTGTACC CCTTGTATTT GCTTCTCCTG ATGGTTGGTC AAATAATAAA 1200

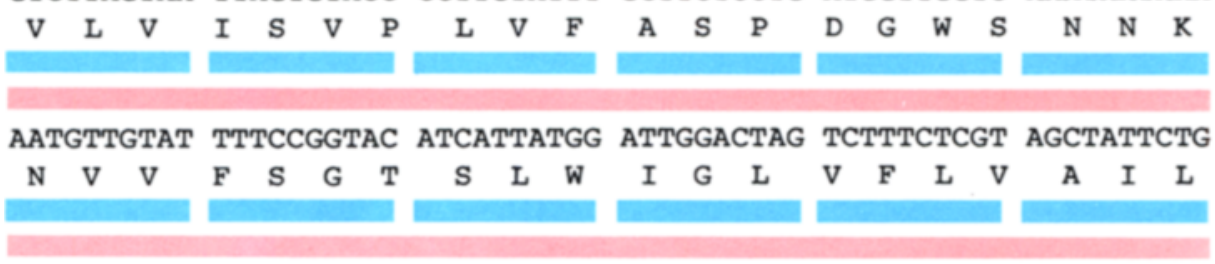

AATTCTCTCA TTTCTTAAAT TAAATTTGGT TAATATTTAG TAACCCCATA AAAAAGAAAT

1320 $\begin{array}{llllll}\mathrm{N} & \mathrm{S} & \mathrm{L} & \mathrm{I} & \mathrm{S} & +\end{array}$

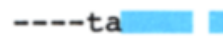

a d / ctttt 


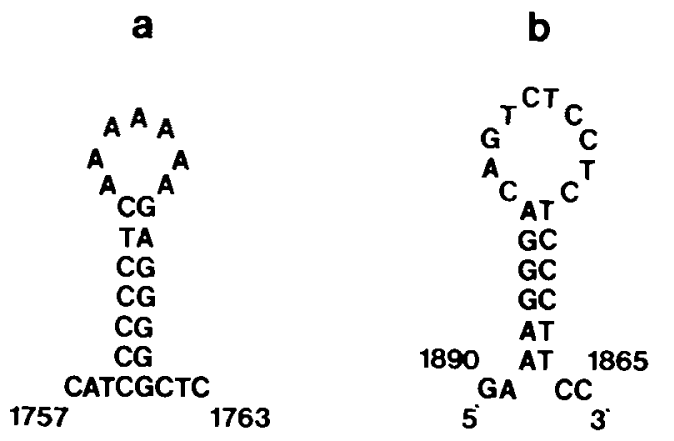

Figure 13. Stem-loop structures close to the putative 3 end of transcripts. a) constitutive transcript family, b) th.e $0.3 \mathrm{~kb}$ light-induced transcript.

\subsection{Open-reading frames}

An open-reading frame which starts before the HindIII site (coordinate 1) extends for 500 bases into the sequenced fragment. It comprises 165 codons. A second, complete ORF extends from 1090 to 1278 and comprises 62 codons. The Shine-Dalgarno $(36,38)$ sequence GGAGG (1076-1080) preceeds the start codon. No other ORFs of significance were found.

There is no homology between the deduced amino-acid sequences of these two ORFs and known primary sequences of chloroplast proteins. It is entirely possible that the ORFs are expressed as functional proteins because in an overlapping sequence from maize $(19,21)$ these ORFs are conserved. $1.3 \mathrm{kbp}$ of a $3 \mathrm{kbp}$ sequence from maize is homologous to the start of the barley sequence. Figure 12 shows the two DNA sequences aligned for maximum homology, together with the deduced amino-acid acid sequences. It can be seen that, despite 26 differences in the first 500 bases, there are only four amino acid changes. In the 62-codon ORF, only one nucleotide and one codon are altered. These five amino acid alterations are conservative substitutions. The Shine-Dalgarno sequence is conserved. This homology in the deduced amino acid sequences as well as the translational signal implies that a strict functional constraint on base substitutions exists and indicates that the ORFs are expressed as proteins.

In maize the long ORF was found to be 473 codons in length (Figure 1). Curiously the start of this ORF is overlapped by a 353-codon ORF. The sequence of the 353-codon ORF is highly homologous to a pea chloroplast gene for the "D2" thylakoid protein (33). Both the 473- and 62-codon ORFs would code for hydrophobic and thus membrane proteins. At the present time there is no further information on the nature of the protein presumably encoded on these genes.

The rest of the maize and barley sequences which overlaps can be compared (Figure 12). Between the two ORFs but in the opposite direction is the tRNA gene for serine (21). The gene is identical in the two species but the immediate flanking regions are only moderately conserved. There are, however, areas of high or complete homology in the apparently noncoding sequences. For example there are only 6 changes in the 90 bases $501-590$ and 4 changes in the 70 bases 971-1040. Differences between the sequences are normally caused by deletions or insertions (e.g. 785-815, 851-935). In two cases the ends of the deletions coincide with stretches of A residues (779-786, 933-939). The high level of sequence homology in much of this "non-coding" region again suggests that there is a functional constraint on base substitutions. It will take an experimental rather than a comparative approach to discover the reason for the constraint.

\subsection{Trancription of $\mathrm{pHvC35}$}

\subsubsection{The constitutive transcripts}

Nine transcripts were found to hybridise to the end of the fragment nearer to the inverted repeat. Northern and S1-mapping studies (Figures 5 and 6 ) indicated that 4 of the transcripts ended beyond 350 and the remaining 5 at around 1812 . The primary transcript is therefore processed from both the 3' and 5' ends. The role of this family of transcripts may be to produce $m R N A s$ for the translation of the D2 protein and the proteins encoded by the 473and 62-codon ORFs. They would also be precursors for the tRNA ${ }^{\text {sly }}$-GCC. A stem and loop structure frequently found at the end of chloroplast transcripts (45), can be formed from 17601780 (Figure 13a).

Although the $3^{\prime}$ end of the $1.8 \mathrm{~kb}$ transcript 

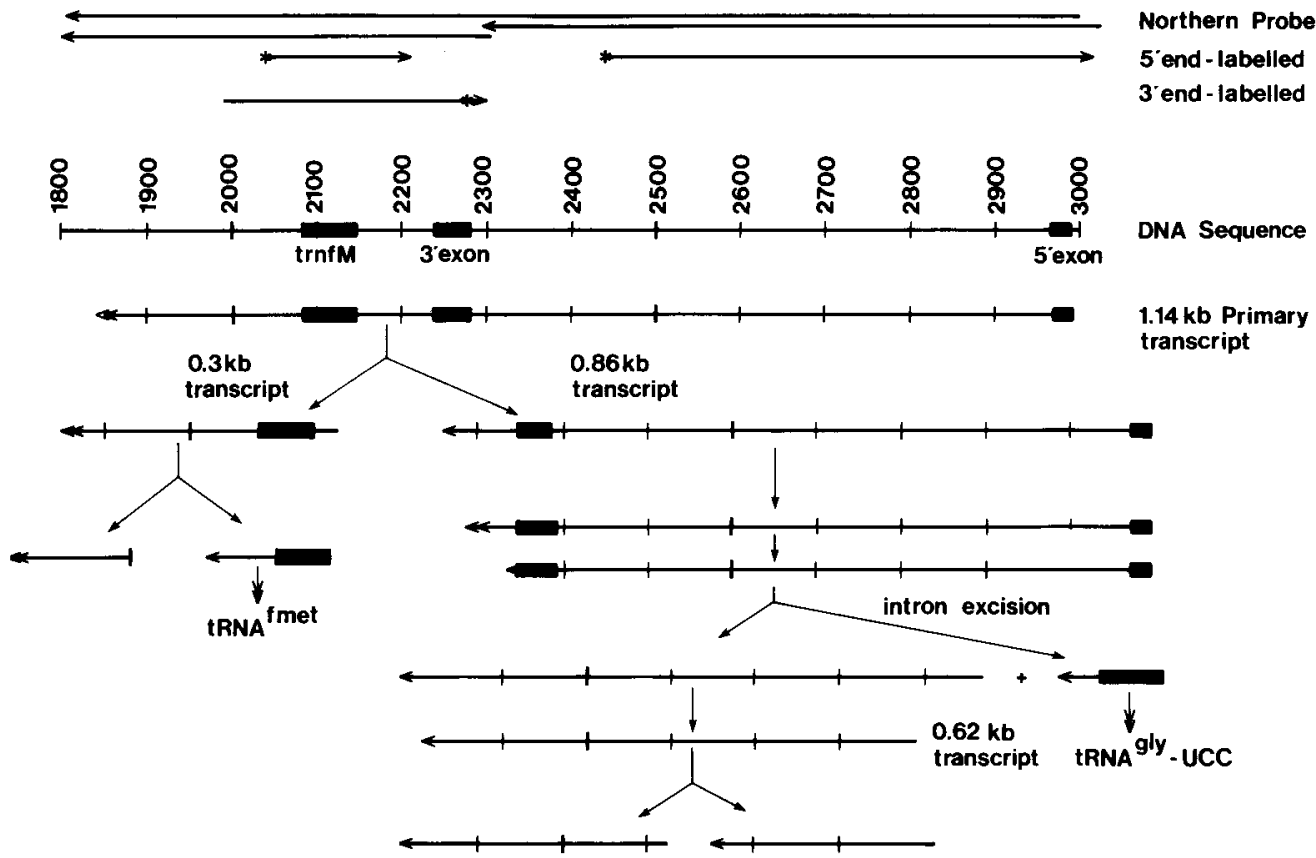

Figure 14. Scheme for the transcription and processing of the trnG-UUC and trnfM loci. Boxes represent coding sequence. Named transcripts refer to the primary $1.14 \mathrm{~kb}$ transcript and the $0.86,0.62$ and $0.3 \mathrm{~kb}$ transcripts identified by Northern hybridisation.

was not determined precisely, its size and position indicate that it could be the mature mRNA for the 473-codon ORF. An mRNA suitable for the 62-codon ORF was not detected. It may have been too small and thus lost during purification of the RNA or during transfer to Genescreen. The lack of promoter sequences prior to the small ORF argues against it being separately transcribed.

The finding of a tRNA gene at the end of a large polycistronic transcript is similar to some transcripts of mammalian mitochondrial genomes (6). The processing of the $5.5 \mathrm{~kb}$ transcript into three mRNAs and into a precursor for a tRNA implies that the primary transcript is processed intercistronically. Multiple and/or polycistronic mRNAs have been found to hybridise to a number of chloroplast genes $(7,20$, $26,30)$. It has been proposed that a transcript encompassing the genes for the $\mathrm{P} 680$ apoprotein, cytochrome $b_{6}$ and subunit IV of the cytochromes $b_{6} / f$ complex is intercistronically processed (26). Many areas of the barley genome were found to hybridise to multiple or large ( $>3$ kb) transcripts (29). Thus, intercistronic processing of polycistronic transcripts is likely to be a general mechanism for the expression of plastid genes.

\subsubsection{The 0.86, 0.62 and $0.3 \mathrm{~kb}$ light- induced transcripts}

This family of transcripts are putative precursors and intermediates in the expression of the trnfM and trnG-UCC genes. The time scale and extents of light-induction are similar, suggesting that they are developmentally related. A scheme for the complex transcription of this region of the DNA has to account for the following ends of transcripts determined by S1-mapping and Northern analyses: 5' 2988, 2888, 2714, 2195 and $2150 ; 3^{\prime} 2238,2178,2167,2000$ and about 1850. A scheme to account for the Northern and S1-mapping data as well as the positions of the genes is shown in Figure 14.

A prokaryotic-like promoter sequence TTGACA - 17 bp - CATAAT was found at 3027-2999 (Figure 10). The major 5' transcript 
start was found at 2988 (Figure 7) 11 bases downstream. As no promoter-like sequence was found prior to the other transcription starts, it is proposed that 2988 is the start of the primary transcript. Northern analysis placed the 3 ' end of the $0.3 \mathrm{~kb}$ transcript at about 1850 . A putative stem and loop transcription terminator sequence is found at $1895-1861$ (Figure 13b). It is therefore likely that the primary transcript is $1.14 \mathrm{~kb}$ in length and extends from 2988 to about 1850 . Failure to detect this transcript by Northern hybridisation suggests that it does not significantly accumulate.

After transcription of the putative $1.14 \mathrm{~kb}$ precursor, the first event is evidently the cleavage of the primary transcript. This would create the 5' starts of the $0.3 \mathrm{~kb}$ transcript found at 2195 or 2150 . This latter position is only 2 bases from the start of the $\operatorname{trn} f M$ gene. Following this step a second cleavage creates the 3' end found by S1-nuclease digestion at 2000 . This cleavage forms two molecules of ca. 150 bases. These molecules and any further processing intermediates would be too small to be detected by Northern hybridisation as performed here. Further processing of both ends of the transcript as well as modified base formation would create the tRNA-fMet.

The other product from the intial cleavage of the putative $1.14 \mathrm{~kb}$ transcript is the extremely abundant $0.86 \mathrm{~kb}$ transcript (Figure 6). The 5' end of this molecule is at or close to the 5 ' base of the first exon of the intron-containing glycine tRNA gene, 2988. 3' ends for this molecule were found at both 2167 and 2178 . Thus, the size of the molecule as determined by S1-mapping $(810$ and $821 \mathrm{~b})$ is close to the size estimated by.Northern analysis. Further processing would create the 3' end at 2238 which is close to the predicted 3' end of the 3' exon of the trnG-UCC gene.

Excision of the intron from the $0.86 \mathrm{~kb}$ transcript would create a 677 b molecule running from 2964-2288. A 5 ' end was located by S1-mapping at 2888. The 3' end of the 0.62 $\mathrm{kb}$ transcript was deduced by Northern analysis to be proximal to 2294 . It is likely therefore that after excision of the intron, the bases between the 5 ' intron junction (2964) and the determined 5' end (2888) are rapidly removed.
If the 3 ' end of the transcript is similarily trimmed to about 2300 , a molecule of $588 \mathrm{~b}$ is created. This is close to the size estimated by Northern analysis $(0.62 \mathrm{~kb})$. Further processing of the metastable $0.62 \mathrm{~kb}$ molecule would create the 5' start observed at 2714 . The role of the intron-containing transcripts is unknown.

After removal of the intron, the $0.86 \mathrm{~kb}$ transcript would be reduced to about $240 \mathrm{~b}$. Further processing of this molecule would create the $\operatorname{trn} G-U C C$ gene product. It is clear that further experiments with smaller S1 probes and capping enzyme are required to substantiate this hypothesis.

\subsubsection{The 0.8 and $1.8 \mathrm{~kb}$ light-induced transcripts}

A 5' end corresponding to either or both of the 0.8 and $1.8 \mathrm{~kb}$ light-induced transcripts was found at $3073 \pm 1$. This is $6-8$ bases downstream from the sequence TTGACA - 18 bp TATTGA (3039-3067) similar to the consensus of bacterial and chloroplast promoters (8). The $0.8 \mathrm{~kb}$ transcript would extend to about 3900 , whereas the $1.8 \mathrm{~kb}$ transcript would extend beyond the end of the sequence. The longer transcript could act as a precursor for the tRNA $^{\text {thr }}$ found at $4112-4183$. The putative end of the shorter transcript falls in a sequence which is both AT-rich and capable of forming large secondary structures (Figure 9a). These features may act as transcription terminators, attenuators or as processing sites. No significant ORFs or other IRNA genes were found in the sequence between 3073 and 4112. It is therefore difficult to suggest a role for the shorter transcript at present.

\subsubsection{The $0.72 \mathrm{~kb}$ light-induced transcript}

Northern analysis indicates that the 3' end of this transcript falls between 3632 and 3795 . This implies that both strands of the DNA in this region are transcribed. Analysis of the sequence of the adjacent chloroplast DNA fragment will be required to elucidate the role of this transcript. 


\subsection{Summary}

The earlier study had indicated that this area of DNA was disproportionately heavily transcribed (29). This has been amply confirmed. Fifteen transcripts totalling $38 \mathrm{~kb}$ have been identified as hybridising under stringent conditions to this $4.3 \mathrm{kbp}$ fragment. Roles have been suggested for 14 of the transcripts. Transcripts hybridise to all but about 140 bases of the DNA. In one area transcripts hybridise to both strands. The promoter sequences (TTGACA etc.) of the 0.86 and $1.8 \mathrm{~kb}$ light-induced transcripts are separated by only 10 bases. It remains to be seen whether the entire chloroplast genome is transcribed as completely as this fragment.

\section{ACKNOWLEDGEMENTS}

We wish to thank S.K. RASMUSSEN for help in the DNA sequencing, LISBETH SEJERSEN and MICHAEL NIELSEN for adapting the computer programs and DITER VON WETTSTEIN for a critical reading of the manuscript. We are also grateful to O. RASMUSSEN, K.W. HENNINGSEN, E. KREBBERS and L. BOGORAD for discussions and permission to study unpublished data. We acknowledge the technical assistance of ANNSoFi Steinholtz, Nina Rasmussen and HANNE THEM NielsEN.

\section{REFERENCES}

1. BERK, A.S. \& P.A. SHARP: Sizing and mapping of early adenovinus mRNAs by gel electrophoresis of S1 endonuclease-digested hybrids. Cell 12, 721732 (1977)

2. BIRNBOIM, H.C. \& J DOLY: A rapid alkaline extraction procedure for screening recombinant DNA. Nucleic Acids Res. 7, 1513-1523 (1979)

3. BOWMAN, C.M \& T.A. DYER: Structural variation and the occurrence of small repeated sequences in the chloroplast genome of wheat and its close relatives. Abstract Nato Advanced Studies Institute FEBS Advanced Course: Molecular Form and Function of the Plant Genome. Renesse, The Netherlands, B2 (1984)

4. Calagan, J.L., R.M. Pirtle, I.L. Pirtle, M.A. Kashdan, H.J. VReman \& B.S. DudOCK: Homology between chloroplast and prokaryote initiator
tRNA. Nucleotide sequence of spinach chloroplast methionine initiator tRNA. J. Biol. Chem. 255, 9981-9984 (1980)

5. Canaday, J., P. Guillemaut \& J.H. Weil: The nucleotide sequences of the initiator transfer RNAs from bean cytoplasm and chloroplasts. Nucleic Acids Res. 8, 999-1008 (1980)

6. Clayton, D.A.: Transcription of the mammalian mitochondrial genome. Ann. Rev. Biochem. 53, 573-594 (1984)

7. CROSSland, L.D., S.R. Rodermel \& L. Bogorad: Single gene for the large subunit of nibulosebisphosphate carboxylase in maize yields two differentially regulated mRNAs. Proc. Natl. Acad. Sci. 81, 4060-4064 (1984)

8. Crouse, E.J., H.J. Bohnert \& J.M. SCHMitT: Chloroplast RNA synthesis. In: Chloroplast Biogenesis. R.J. Ellis ed., Seminar Series, Soc. Exp. Biol,, Cambridge University Press, Vol. 21, 83-136 (1984)

9. DenO, H. \& M. Sugiura: Chloroplast tRNA ${ }^{\text {Gly }}$ gene contains a long intron in the D stem: nucleotide sequences of tobacco chloroplast genes for tRNA $^{\text {Cty }}$ (UCC) and tRNA ${ }^{\text {Arg }}$ (UCU). Proc. Natl. Acad. Sci. 81, 405-408 (1984)

10. Deno, H., A. Kato, K. Shinozaki \& M. Sugiura: Nucleotide sequences of tobacco chloroplast genes for elongator tRNA ${ }^{\mathrm{Met}}$ and $\mathrm{tRNA} \mathrm{V}^{\mathrm{Val}}$ (UAC): the tRNA ${ }^{\mathrm{val}}$ (UAC) gene contains a long intron. Nucleic Acids Res. 10, 7511-7520 (1982)

11. Gordon, K.H.J., E.J. Crouse, H.J. Bohnert \& R.G.HERRMANN: Physical mapping of differences in chloroplast DNA of five wild-type plastomes in Oenothera subsection Euoenothera. Theor. Appl. Genetics 61, 373-384 (1982)

12. HollingsworTh, M.J. \& R.B. HAllick: Euglena gracilis chloroplast transfer RNA transcription units. Nucleotide sequence analysis of a $t R N A^{T y r}$ tRNA $^{\text {His }}$-tRNA ${ }^{\text {Met }}$-tRNA ${ }^{\text {Trp }}$-tRNA ${ }^{\text {Glo }}$-tRNA ${ }^{\text {Gly }}$ gene cluster. J. Biol. Chem. 257, 12795-12799 (1982)

13. HU, N.-T. \& J. MessinG: The making of strand-specific M13 probes. Gene 17, $271-277$ (1982)

14. KaRABIN, G.D. \& R.B. HALLICK: Euglena gracilis chloroplast transfer RNA transcription units. Nucleotide sequence analysis of a tRNA ${ }^{\mathrm{Ih}}-\mathrm{tRNA}{ }^{\mathrm{Cly}}$ tRNA ${ }^{\text {Mel }}$-tRNA ${ }^{\text {set }}$-tRNA ${ }^{\text {Gin }}$ gene cluster. J. Biol. Chem. 258, 5512-5518 (1983)

15. KASHDAN, M.A. \& B.S. DudoCK: Structure of a spinach chloroplast threonine tRNA gene. J. Biol. Chem. 257, 1114-1116 (1982)

16. Kashdan, M.A., R.M. Pirtle, I.L. Pirtle, J.L. Calagan, H.J. VReman \& B.S. Dudock: Nucleotide sequence of a spinach chloroplast threonine tRNA. J. Biol. Chem. 255, 8831-8835 (1980)

17. КосH, W., K. EdWARdS \& H. KöSSEL: Sequencing 
of the 16S-23S spacer in a ribosomal RNA operon of Zea mays chloroplast DNA reveals two split tRNA genes. Cell 25, 203-213 (1981)

18. Koller, B., J.C. Gingrich, G.L. Stiegler, M.A. Farley, H. Delius \& R.B. Hallick: Nine introns with conserved boundary sequences in the Euglena gracilis chloroplast ribulose-1,5-bisphosphate carboxylase Gene. Cell 36, 545-553 (1984)

19. Krebbers, E.T.: Ph. D. Thesis. Harvard University (1983)

20. Krebbers, E.T., I.M. LARRINUA, L. McINTOSH \& L. BOGORAD: The maize chloroplast genes for the $\beta$ and $\varepsilon$ subunits of the photosynthetic coupling factor $\mathrm{CF}_{1}$ are fused. Nucleic Acids Res. 10, 49855002 (1982)

21. KRebiers, E.,A. Steinmetz \& L. Bogorad: DNA sequences for the Zea mays TRNA genes $T V$-UAC and tS-UGA: $t V-U A C$ contains a large intron. Plant Mol. Biol. 3, 13-20 (1984)

22. Kuntz, M., J.H. WeIL \& A. Steinmetz: Nucleotide sequence of a $2 \mathrm{kbp} \mathrm{BamH} 1$ fragment of Vicia faba chloroplast DNA containing the genes for threonine, glutamic acid and tyrosine transfer RNAs. Nucleic Acids Res. 12, 5037-5041 (1984)

23. MaXAm, A.M. \&W. GilberT: Sequencing end-labelled DNA with base-specific chemical cleavages. Meth. Enzymol. 65, 499-560 (1980)

24. MesSING, J. \& J. VIEIRA: A new pair of M13 vectors for selecting either DNA strand of double digested restriction fragments. Gene 19, 269-276 (1982)

25. MiCHEL, F. \& B. DUjon: Conservation of RNA secondary structures in two intron families including mitochondrial-, chloroplast-, and nuclear-encoded members. EMBO J. 2, 33-38 (1983)

26. Morris, J. \& R.G. HerrmanN: Nucleotide sequence of the gene for the P680 chlorophyll a apoprotein of the photosystem II reaction center from spinach. Nucleic Acids Res. 12, 2837-2850 (1984)

27. PAlmer, J.D. \& W.F. ThOMpson: Chloroplast DNA rearrangements are more frequent when a large inverted repeat sequence is lost. Cell 29, 537-550 (1982)

28. Pirtle, R.M., J.L. Calagan, I.L. Pirtle, M.A. Kashdan, H.S. VReman \& B.S. Dudock: The nucleotide sequence of spinach chloroplast methionine elongator tRNA. Nucleic Acids Res. 9, 183-188 (1981)

29. POUlSEN, C.: The barley chloroplast genome: Physical structure and transcriptional activity in vivo. Carlsberg Res. Commun. 48, 57-80 (1983)

30. Poulsen, C.: Two mRNA species differing by 258 nucleotides at the 5' end are formed from the barley chloroplast rbcL gene. Carlsberg Res. Commun. 49, 89-104 (1984)

31. Oliver, R.P., C.G. Kannangara \& S.P. Gough:
Structure and functions of a highly transcribed fragment of barley chloroplast DNA. An RNA involved in $\Delta$-aminolaevulinate biosynthesis. Abstract presented at the NATO Advanced Studies Institute. FEBS Advanced Course: Molecular Form and Function of the Plant Genome. Renesse, The Netherlands, B22 (1984)

32. Oliver, R.P.\&C. POULSEN: The barley chloroplast genome: Analysis of a highly transcribed region. Proc. VI Int. Congr. Photosynthesis, Brussels, Belgium. ed. C. Sybesma, Martinus Nijhoff/W Junk. Publ. vol. IV part 5 pp. 521-524 (1984)

33. Rasmussen, O.F., G. Bookjans, B.M. StumMANN \& K.W. HENNINGSEN: Localisation and nucleotide sequence of the gene for the membrane polypeptide D2 from pea chloroplast DNA. Plant Mol. Biol. 3, 191-199 (1984)

34. Rasmussen, S.K., H.E. HoPP \& A. BRandT: Nucleotide sequences of DNA clones for $\mathrm{B} 1$ hordein polypeptides. Carlsberg Res. Commun. 48, 187 199 (1983)

35. SANGer, F., S. Nicklen \& A.R. COUlson: DNA sequencing unit chain-terminating inhibitors. Proc. Natl. Acad. Sci. 74, 5463-5467 (1977)

36. SCHWARZ, Z. \& H. KösSEL: The primary structure of $16 \mathrm{~S}$ rDNA from Zea mays chloroplast is homologous to E. coli 16S rDNA. Nature 283, 739-742 (1980)

37. Selden, R.F., A. Steinmetz, L. Mcintosh, L Bogorad, G. Burkard, M. Mubumbila, M. KunTZ, EJ Crouse \& J.H. WeIL: Transfer RNA genes of Zea mays chloroplast DNA. Plant Molec. Biol. 2, 141.153 (1983)

38. Shine, J. \& L. Dalgarno: Determinant of cistron specificity in bacterial ribosomes. Nature 254: 34-38 (1975)

39. Steinmetz, A., E.J. Gubbins \& L. Bogorad: The anticodon of the maize chloroplast gene for tRNA $\mathrm{A}_{\text {lIAA }}^{\text {Leu }}$ is split by a large intron. Nucleic Acids Res. 10, 3027-3037 (1982)

40. Sugiura, M. K. Shinozaki, H. Deno, T. KamoGASHIRA \& M. SUGITA: Structure of tobacco chloroplast tRNA genes. Int. tRNA Workshop. Abstract. Hakone, Japan (1983)

41. Takaiwa, F. \& M. Sugiura: Nucleotide sequence of the $16 \mathrm{~S}-23 \mathrm{~S}$ spacer region in a rRNA gene cluster from tobacco chloroplast DNA. Nucleic Acids Res. 10, 2665-2676 (1982)

42. Tassopulu, D. \& S.D. Kung: Nicotiana chloroplast genome 6. Deletion and hot spot - a proposed origin of the inverted repeats. Theor. Appl. Genet. 67, 185-193 (1984)

43. Weil, J.H., M. Mubumbil.A, M. Kuntz, M. Keller, E.J. Crouse, G. Burkard, P. GuilleMAUT, R. SElden, L. MCINTOSh, L. Bogorad. W. 
Loffelhardt, H. MuCKe. H.J. Bohnert, A. DieTRICH, G. SOUCiET, B. Colas, P. Imbault \& V. SARONTOGLOU: Comparative studies on tRNA and aminoacyl-tRNA synthetases from various photosynthetic organism. In: Structure and Function of Plant Genomes Eds. O. Ciferri \& L. Dure. In: ASI Ser. A, Life Sciences vol 63. Plenum Press N.Y. pp. 167-180 (1983)

44. Wettstein, D. von, C. Poulsen, R.P. Oliver, S.P. Gough, C.G. Kannangara, B.L. Møller \&
D. SimPSON: Concerted interplay of chloroplast and nuclear genes in the formation of the photosynthetic apparatus. Proc. XV Int. Congr. Genetics. New Delhi, India 1984 (in press)

45. Whitfield, P.R.\& W. BottomLeY: Organisation and structure of chloroplast genes. Ann. Rev. Plant Physiol. 34, 279-310 (1983)

46. ZuRawski, G. \& M.T. CleGG: The barley chloroplast DNA atpBE, trnM2 and trnV1 loci. Nucleic Acids Res. 12, 2549-2559 (1984)

Accepted by: H. KLENOW, E. LUND and S.O. ANDERSEN 